\title{
Focal Adhesion Kinase Acts Downstream of EphB Receptors to Maintain Mature Dendritic Spines by Regulating Cofilin Activity
}

\author{
Yang Shi, ${ }^{1}$ Crystal G. Pontrello, ${ }^{1}$ Kathryn A. DeFea, ${ }^{1}$ Louis F. Reichardt,${ }^{2}$ and Iryna M. Ethell ${ }^{1}$ \\ ${ }^{1}$ Division of Biomedical Sciences and Neuroscience Program, University of California, Riverside, Riverside, California 92521, and ${ }^{2}$ Department of \\ Physiology, University of California, San Francisco, San Francisco, California 94158
}

\begin{abstract}
Dendritic spines are the postsynaptic sites of most excitatory synapses in the brain and are highly enriched in polymerized F-actin, which drives the formation and maintenance of mature dendritic spines and synapses. We propose that suppressing the activity of the actinsevering protein cofilin plays an important role in the stabilization of mature dendritic spines, and is accomplished through an EphB receptor-focal adhesion kinase (FAK) pathway. Our studies revealed that Cre-mediated knock-out of loxP-flanked fak prompted the reversion of mature dendritic spines to an immature filopodial-like phenotype in primary hippocampal cultures. The effects of FAK depletion on dendritic spine number, length, and morphology were rescued by the overexpression of the constitutively active FAK $^{\mathrm{Y} 397 \mathrm{E}}$, but not FAK ${ }^{\mathrm{Y} 397 \mathrm{~F}}$, indicating the significance of FAK activation by phosphorylation on tyrosine 397. Our studies demonstrate that FAK acts downstream of EphB receptors in hippocampal neurons and EphB2-FAK signaling controls the stability of mature dendritic spines by promoting cofilin phosphorylation, thereby inhibiting cofilin activity. While constitutively active nonphosphorylatable cofilin ${ }^{\text {S3A }}$ induced an immature spine profile, phosphomimetic cofilin ${ }^{\text {S3D }}$ restored mature spine morphology in neurons with disrupted EphB activity or lacking FAK. Further, we found that EphB-mediated regulation of cofilin activity at least partially depends on the activation of Rho-associated kinase (ROCK) and LIMK-1. These findings indicate that EphB2-mediated dendritic spine stabilization relies, in part, on the ability of FAK to activate the RhoA-ROCK-LIMK-1 pathway, which functions to suppress cofilin activity and inhibit cofilin-mediated dendritic spine remodeling.
\end{abstract}

\section{Introduction}

Dendritic spines are small protrusions on the surface of dendrites that receive the majority of excitatory synapses, and changes in their morphology are implicated in synaptic plasticity and longterm memory (Harris, 1999; Hering and Sheng, 2001; Yuste and Bonhoeffer, 2001; Carlisle and Kennedy, 2005). Many celladhesion molecules are located on the surface of dendritic spines and play important roles in dendritic spine formation and plasticity, including Eph receptors and ephrins, neuroligins, and neurexins, as well as cadherins and integrins (Ethell and Pasquale, 2005; Sheng and Hoogenraad, 2007). These cell surface proteins mediate dendritic spine communications with presynaptic terminals, glial cells, or components of the extracellular matrix, and trigger intracellular signaling cascades that influence actin cytoskeletal organization in dendritic spines.

Received Sept. 30, 2008; revised May 20, 2009; accepted May 23, 2009.

This work is supported by National Institutes of Health Grants MH67121 (I.M.E.) and NS19090 (L.F.R.). We thank Dr. Donna Webb (University of Virginia) for the gift of the pYFP-FAK construct, Dr. Marc Schmidt-Supprian (Harvard Medical School) for donation of the PPGK-Cre plasmid, and Dr. James Bamburg (Colorado State University) for the generous gift of the anti-phospho-cofilin and anti-cofilin antibodies. We are grateful to Dr. David Carter for his advice on confocal microscopy. We also thank Dr. Douglas Ethell and members of the Ethell laboratory for helpful discussions and comments on this manuscript.

Correspondence should be addressed to Dr. Iryna Ethell, Biomedical Sciences, University of California, Riverside, 900 University Avenue, Riverside, CA 92521-0121. E-mail: iryna.ethell@ucr.edu.

DOI:10.1523/JNEUROSCI.4681-08.2009

Copyright $\odot 2009$ Society for Neuroscience $\quad$ 0270-6474/09/298129-14\$15.00/0
Actin is the major cytoskeletal component that is accumulated in dendritic spines (Fischer et al., 1998; Matus, 2000; Carlisle and Kennedy, 2005). Rapid assembly and disassembly of actin drives the formation of dendritic spines and their morphological plasticity (Ethell and Pasquale, 2005; Lippman and Dunaevsky, 2005). Several signaling cascades link cell surface receptors to intracellular factors that directly regulate actin assembly or remodeling, such as the actin-severing protein cofilin. Our current studies suggest that long-lasting EphB receptor signaling in mature dendritic spines suppresses cofilin-mediated dendritic spine remodeling through the recruitment and activation of focal adhesion kinase (FAK). FAK is a nonreceptor tyrosine kinase that is widely expressed in different cell types and is implicated in a wide range of biological processes, including tissue formation, cell migration, and tumor progression (Parsons et al., 2000; Abbi and Guan, 2002; Mitra et al., 2005). In the brain, FAK has been shown to regulate neurite outgrowth and branching in developing neurons (Menegon et al., 1999; Beggs et al., 2003; Contestabile et al., 2003; Rico et al., 2004). However, the role of FAK in dendritic spine maintenance and plasticity still remains unclear.

Here we show that FAK activity, which can be modulated by EphB receptors, plays an important role in the maintenance of mature dendritic spines by suppressing the activity of actinsevering cofilin through phosphorylation. Cre-mediated knockout (KO) of loxP-flanked fak in 14 and $21 \mathrm{~d}$ in vitro (DIV) hippocampal neurons induced the remodeling of existing dendritic 
spines and actin reorganization. The effects of FAK depletion on dendritic spine morphology and actin reorganization were rescued by overexpression of the constitutively active $\mathrm{FAK}^{\mathrm{Y} 397 \mathrm{E}}$, but not the FAK ${ }^{\mathrm{Y} 397 \mathrm{~F}}$, indicating the importance of FAK activation in dendritic spine maintenance. Constitutively active $\mathrm{FAK}^{\mathrm{Y} 397 \mathrm{E}}$ also restored mature dendritic spine morphology disrupted by inhibiting EphB receptor activity with dominant-negative EphB2 (dnEphB2), indicating that FAK acts downstream of EphB receptors in hippocampal neurons. The ability of FAK to promote mature dendritic spine morphology also depended on cofilin activity. We show that the inhibition of EphB receptor activity or Cre-mediated fak deletion enhances cofilin-mediated dendritic spine remodeling, which can be blocked by overexpression of phosphomimetic cofilin ${ }^{\text {S3D }}$, but not by nonphosphorylatable, constitutively active cofilin ${ }^{\mathrm{S} 3 \mathrm{~A}}$. Our findings indicate that $\mathrm{EphB}$ receptors control the stability of mature dendritic spines, in part, through LIMK-mediated regulation of cofilin activity.

\section{Materials and Methods}

Expression vectors. The expression vectors used were: pEGFP-N1 and pDsRed-C2 (Clontech), pcDNA3-EphB2 and pcDNA3-EphB2 ${ }^{\text {K662R }}$ (dnEphB2) (Ethell et al., 2001), pPGK-Cre (from Dr. Marc SchmidtSupprian, Harvard Medical School, Boston, MA), pYFP-FAK (from Dr. Donna Webb, University of Virginia, Charlottesville, VA) (Webb et al., 2004), pcDNA3-GFP-cofilin, pcDNA3-GFP-cofilin ${ }^{\text {S3A }}$, and pcDNA3GFP-cofilin ${ }^{\mathrm{S} 3 \mathrm{D}}$. Single amino acid point mutations in FAK were generated by mutagenesis of tyrosine (Y) 397 into phenylalanine (F) or glutamate (E); proline (P) 878 into alanine (A); and leucine (L) 1034 into serine (S) using a QuikChange Site-Directed Mutagenesis Kit (Stratagene).

Antibodies. The primary antibodies used were as follows: rabbit antiFAK [Santa Cruz Biotechnologies; $1 \mu \mathrm{g} / \mathrm{ml}$ for Western blot (WB) and 4 $\mu \mathrm{g} / \mathrm{ml}$ for immunocytochemistry (ICC)], rabbit anti-pY ${ }^{397}$ FAK (BIOSOURCE International; $0.25 \mu \mathrm{g} / \mathrm{ml}$ for $\mathrm{WB}$ ), rabbit anti-Src (BIOSOURCE International; $1 \mu \mathrm{g} / \mathrm{ml}$ for $\mathrm{WB}$ ), mouse anti-paxillin (BD Transduction Laboratories; $2 \mu \mathrm{g} / \mathrm{ml}$ for $\mathrm{WB}$ ), rabbit anti-pY ${ }^{31}$ paxillin (BIOSOURCE International; $1 \mu \mathrm{g} / \mathrm{ml}$ for $\mathrm{WB}$ ), and rabbit anti$\operatorname{Tyr}(\mathrm{P})^{418}$ Src (BIOSOURCE International; $1 \mu \mathrm{g} / \mathrm{ml}$ for WB), rabbit anti- $\beta 3$ integrin (AB1932, Millipore Bioscience Research Reagents; 2 $\mu \mathrm{g} / \mathrm{ml}$ for WB), goat anti-EphB2 (R \& D Systems; $0.2 \mu \mathrm{g} / \mathrm{ml}$ for WB), rabbit anti-Cre (69050-3, Novagen; $2 \mu \mathrm{g} / \mathrm{ml}$ for ICC), mouse anti-FLAG (Sigma; $1 \mu \mathrm{g} / \mathrm{ml}$ for ICC), rabbit anti-phospho-LIMK-1/2 (Cell Signaling; 1:1000 for WB), rabbit anti-LIMK-1 (Millipore Bioscience Research Reagents; $0.76 \mu \mathrm{g} / \mathrm{ml}$ for WB), rabbit anti-cofilin [ACFL02, Cytoskeleton; $0.25 \mu \mathrm{g} / \mathrm{ml}$ for $\mathrm{WB} ; 1 \mu \mathrm{g}$ per $20 \mu \mathrm{l}$ of protein A-agarose beads (Sigma)], and rabbit anti-phospho-cofilin (S3) (ab12866, Abcam; 1:1000 for WB). The affinity-purified rabbit anti-phospho-cofilin (4321; 1 $\mu \mathrm{g} / \mathrm{ml}$ for ICC) and mouse anti-cofilin (MAb22; $15 \mu \mathrm{g} / \mathrm{ml}$ for ICC) antibodies were generous gifts from Dr. James Bamburg (Colorado State University, Fort Collins, CO).

Hippocampal neuronal cultures and transfection. Cultures of hippocampal neurons were prepared from embryonic day 15 (E15) or E16 mice as previously described (Shi and Ethell, 2006). Briefly, after treatment with papain $(0.5 \mathrm{mg} / \mathrm{ml})$ and DNase $(0.6 \mu \mathrm{g} / \mathrm{ml})$ for $20 \mathrm{~min}$ at $37^{\circ} \mathrm{C}$ and mechanical dissociation, cells were plated on glass coverslips or plastic dishes coated with poly-DL-ornithine $(0.5 \mathrm{mg} / \mathrm{ml})$ and laminin $(5$ $\mu \mathrm{g} / \mathrm{ml})$. The cells were cultured in Neurobasal medium with $25 \mu \mathrm{M}$ glutamine, $1 \%$ penicillin-streptomycin, and $\mathrm{B} 27$ supplement (Invitrogen) under a $5 \% \mathrm{CO}_{2} / 10 \% \mathrm{O}_{2}$ atmosphere at $37^{\circ} \mathrm{C}$. The cultures were transfected at 12 or 19 DIV using the calcium phosphate method as previously described (Jiang and Chen, 2006; Shi and Ethell, 2006). The protocol achieves high transfection efficiency $(10-20 \%)$, a high cotransfection rate $(\sim 95 \%)$, and low cell toxicity.

Conditional fak KO. Hippocampal neurons were harvested from E15E16 fak conditional (Cre-loxP) KO mice (Beggs et al., 2003) and cultured as described above. The pPGK-Cre vector was obtained from Dr. Marc Schmidt-Supprian (Harvard Medical School). The cultures were tran- siently transfected at 12 DIV or 19 DIV using the calcium phosphate method. The neurons were transfected with pEGFP or pDsRed to visualize dendritic spine morphology and/or with pPGK-Cre to abolish FAK expression. For FAK rescue experiments, the neurons were cotransfected with pEGFP, pEGFP plus pPGK-Cre, or pEGFP plus pPGK-Cre plus one of the following: pYFP-FAK, pYFP-FAK ${ }^{\mathrm{Y} 397 \mathrm{~F}}$, pYFP-FAK $^{\mathrm{Y} 397 \mathrm{E}}$, pYFPFAK $^{\mathrm{P} 878 \mathrm{~A}}$, or pYFP-FAK ${ }^{\mathrm{L} 1034 \mathrm{~S}}$. For FAK overexpression experiments, the neurons were transfected with pEGFP, pYFP-FAK, pYFP-FAK ${ }^{\mathrm{Y} 397 \mathrm{~F}}$, pYFP-FAK $^{\mathrm{Y} 397 \mathrm{E}}$, or pYFP-FAK ${ }^{\mathrm{L} 1034 \mathrm{~S}}$. For cofilin experiments, the neurons were transfected with pDsRed, pDsRed plus pPGK-Cre, or pDsRed plus pPGK-Cre plus one of the following: pcDNA3-GFP-wt cofilin, pcDNA3-GFP-cofilin ${ }^{\text {S3A }}$, or pcDNA3-GFP-cofilin ${ }^{\text {S3D }}$. At 14 DIV or 21 DIV, the cultures were fixed and processed for indirect immunofluorescence. Dendritic spines were visualized by GFP or DsRed fluorescence, counted, and measured as described below in Image analysis. Cre expression was detected in the nuclei of the pEGFP/pPGK-Cre-transfected neurons by immunostaining. The analysis has shown that $95 \pm 7 \%$ of GFPexpressing neurons $(n=238)$ were also positive for Cre in pEGFP/ pPGK-Cre-transfected cultures. Moreover, FAK depletion was assessed through FAK immunofluorescence labeling. The dendrites of double pEGFP/pPGK-Cre-transfected neurons showed significantly lower FAKimmunoreactive fluorescence at $14 \operatorname{DIV}(18 \pm 11 \%, n=14)$ than control GFP-transfected neurons (100\%) (supplemental Fig. 1, available at www. jneurosci.org as supplemental material). The FAK immunoreactivity was restored to control levels in dendrites of GFP/Cre-expressing neurons that were transfected with pYFP-FAK $(90 \pm 7 \%, n=14)$. The values represent mean $\pm \mathrm{SD}$.

Activation and inhibition of the EphB2 receptor. To activate the EphB2 receptor in cultured hippocampal neurons, we used ephrinB2-Fc (R \& D Systems), preclustered with anti-human Fc antibody (Jackson ImmunoResearch Laboratories) before the application. To precluster, ephrinB2-Fc or control human Fc fragments were mixed with goat antihuman Fc antibody in a 2:1 ratio and incubated on ice for $1 \mathrm{~h}$ before application to the cultured neurons for 5, 15, 30, or $60 \mathrm{~min}$. To inhibit EphB receptor activity, cultured hippocampal neurons were transfected with pcDNA3-EphB2 ${ }^{\mathrm{K} 662 \mathrm{R}}$ (dnEphB2) (Ethell et al., 2001) at 12 or 19 DIV. For FAK rescue experiments, the neurons were cotransfected with pEGFP, pEGFP plus pcDNA3-dnEphB2 ${ }^{\mathrm{K} 662 \mathrm{R}}$, or pEGFP plus pcDNA3dnEphB2 ${ }^{\text {K662R }}$ plus one of the following: pYFP-FAK, pYFP-FAK ${ }^{\mathrm{Y} 397 \mathrm{~F}}$ or pYFP-FAK ${ }^{\mathrm{Y} 397 \mathrm{E}}$. For cofilin experiments, the neurons were transfected with pDsRed, pDsRed plus pcDNA3-dnEphB2 ${ }^{\mathrm{K} 662 \mathrm{R}}$, or pDsRed plus pcDNA3-dnEphB2 ${ }^{\mathrm{K} 662 \mathrm{R}}$ plus one of the following: pcDNA3GFP-wt cofilin, pcDNA3-GFP-cofilin ${ }^{\text {S3A }}$, or pcDNA3-GFP-cofilin ${ }^{\text {S3D }}$. Two days after transfection, at 14 or 21 DIV, the cultures were fixed and processed for immunostaining. Dendritic spines were visualized by GFP or DsRed fluorescence, counted, and measured as described below in Image analysis. The overexpression of Flag-tagged dnEphB2 ${ }^{\mathrm{K} 662 \mathrm{R}}$ was confirmed by immunostaining against Flag. The expression levels of transfected FAK constructs were assessed as the ratio of exogenous protein to endogenous protein by measuring the immunofluorescence signal in neighboring transfected (GFP or DsRed positive) and untransfected neurons immunostained with anti-FAK antibody. The dendrites of neurons transfected with pYFP-FAK showed significantly higher FAKimmunoreactive fluorescence $(188 \pm 36 \%, n=12)$ than those of untransfected neurons (100\%). Expression of GFP-tagged cofilin constructs was confirmed by GFP fluorescence.

Immunocytochemistry. Hippocampal neurons (14 or 21 DIV) were fixed in $2 \%$ paraformaldehyde, permeabilized in $0.1 \%$ Triton X-100 or $0.2 \mathrm{mg} / \mathrm{ml}$ saponin, and then blocked in PBS containing 5\% normal goat serum and $1 \%$ BSA. Dendritic spines and filopodia were visualized by GFP fluorescence. To detect polymerized filamentous actin (F-actin), the cultures were incubated with rhodamine-coupled phalloidin (1:100; $\mathrm{R}-415$; Invitrogen). The primary antibodies used were the following: rabbit anti-Cre (69050-3, Novagen; $2 \mu \mathrm{g} / \mathrm{ml}$ ); mouse anti-FLAG (Sigma; $1 \mu \mathrm{g} / \mathrm{ml}$ ); rabbit anti-FAK (Santa Cruz Biotechnologies, $4 \mu \mathrm{g} / \mathrm{ml}$ ); mouse anti-FAK (BD; $5 \mu \mathrm{g} / \mathrm{ml}$ ); mouse anti-PSD-95 (clone 6G6, Affinity BioReagents, $33 \mu \mathrm{g} / \mathrm{ml}$ ); and mouse anti-synaptophysin (SVP-38, Sigma, 61 $\mu \mathrm{g} / \mathrm{ml})$. The secondary antibodies used were the following: $4 \mu \mathrm{g} / \mathrm{ml} \mathrm{Al}$ exa Fluor 488-conjugated anti-mouse IgG, $4 \mu \mathrm{g} / \mathrm{ml}$ Alexa Fluor 594- 
conjugated anti-mouse IgG, $4 \mu \mathrm{g} / \mathrm{ml}$ Alexa Fluor 660-conjugated antimouse IgG, $4 \mu \mathrm{g} / \mathrm{ml}$ Alexa Fluor 350-conjugated anti-mouse IgG, 4 $\mu \mathrm{g} / \mathrm{ml}$ Alexa Fluor 594-conjugated anti-rabbit IgG, $4 \mu \mathrm{g} / \mathrm{ml}$ Alexa Fluor 350 -conjugated anti-rabbit IgG, or $4 \mu \mathrm{g} / \mathrm{ml}$ Alexa Fluor 488 -conjugated anti-rabbit IgG. Immunostaining was analyzed under a confocal laserscanning microscope (model LSM 510; Carl Zeiss MicroImaging).

Live imaging. Time-lapse imaging was performed under an inverted fluorescent microscope (model TE2000; Nikon) with a $40 \times$ air Fluor objective and monitored by a 12-bit CCD camera (model ORCA-AG; Hamamatsu) using Image-Pro software (Media Cybernetics). During imaging, the cultures were maintained in Hank's solution supplemented with $1.8 \mathrm{mM} \mathrm{CaCl}_{2}, 0.45 \%$ glucose, and $0.1 \% \mathrm{BSA}$ at $37^{\circ} \mathrm{C}$ and $5 \% \mathrm{CO}_{2}$, and images were captured at 3 min intervals for $1 \mathrm{~h}$.

Ratio imaging of total/phospho-cofilin. The cultured hippocampal neurons were transfected with pEGFP, pYFP-FAK, pYFP-FAK ${ }^{\mathrm{Y} 397 \mathrm{~F}}$, pYFPFAK $^{\mathrm{Y} 397 \mathrm{E}}$, or pYFP-FAK $^{\mathrm{L} 1034 \mathrm{~S}}$ at 12 DIV using the calcium phosphate method and processed for immunocytochemistry at 14 DIV as follows. The neurons were fixed for $30 \mathrm{~min}$ in $2 \%$ paraformaldehyde in PBS or cytoskeletal preservation buffer containing $10 \mathrm{~mm}$ MES, pH 6.1, $138 \mathrm{~mm}$ $\mathrm{KCl}, 3 \mathrm{~mm} \mathrm{MgCl}, 10 \mathrm{~mm}$ EGTA, and $0.32 \mathrm{M}$ sucrose. The cultures were washed in PBS and permeabilized in $0.5 \%$ Triton X-100 for $10 \mathrm{~min}$ and then blocked in PBS containing 5\% normal goat serum and 1\% BSA. The cultures were immunostained for phospho-cofilin with affinity-purified rabbit anti-phospho-cofilin antibody $(4321 ; 1 \mu \mathrm{g} / \mathrm{ml})$ and for total cofilin with mouse anti-cofilin antibody (MAb22; $15 \mu \mathrm{g} / \mathrm{ml}$; both are generous gifts from Dr. James Bamburg). The secondary antibodies used were $4 \mu \mathrm{g} / \mathrm{ml}$ Alexa Fluor 660-conjugated anti-mouse IgG and $4 \mu \mathrm{g} / \mathrm{ml}$ Alexa Fluor 594-conjugated anti-rabbit IgG. Fluorescence was analyzed using a confocal laser-scanning microscope (model LSM 510; Carl Zeiss MicroImaging). A series of five high-resolution optical sections $(1024 \times 1024$ pixel format) were taken for each neuron with a $63 \times$ water-immersion objective (1.2 numerical aperture), $1 \times$ zoom at $0.5 \mu \mathrm{m}$ step intervals $(z$-stack). All images were acquired under identical conditions. Each $z$-stack was collapsed into a single image by projection (Zeiss LSM Image software), converted to a tiff file, and analyzed using Image-Pro Plus software. Seven to 10 neurons were randomly selected for each experimental group, and three to four proximal dendrites per each neuron were analyzed. The levels of phospho-cofilin and total cofilin were assessed by measuring the immunofluorescence signals in dendrites of neighboring transfected (GFP positive) and untransfected neurons immunostained with anti-phospho-cofilin and anti-cofilin antibodies. The background fluorescence was subtracted. The phospho-cofilin levels or ratio of total/ phospho-cofilin in transfected neurons was normalized against the phospho-cofilin levels or ratio of total/phospho-cofilin in untransfected neurons, respectively. Three independent experiments were performed for each condition. Statistical differences between transfected and untransfected neurons were compared by Student's $t$ test. Statistical differences for multiple groups were assessed by one-way ANOVA followed by Newman-Keuls post hoc tests.

Image analysis. The dendritic morphology and F-actin organization were examined in 14 DIV or 21 DIV hippocampal neurons as previously described (Moeller et al., 2006; Shi and Ethell, 2006). The details of the analysis are described in the supplemental Methods (available at www. jneurosci.org as supplemental material).

Biochemical assays. For EphB2 activation, 14 DIV hippocampal neurons were treated with $2 \mu \mathrm{g} / \mathrm{ml}$ ephrin B2-Fc or $2 \mu \mathrm{g} / \mathrm{ml}$ control Fc for 15 min, and lysed in ice-cold TBS (25 mM Tris, pH 7.4;0.15 mM NaCl) containing $1 \%$ Triton X-100, $5 \mathrm{~mm}$ EDTA, $0.5 \mathrm{~mm}$ pervanadate, and protease inhibitor mixture (Sigma). Cell lysates were cleared by centrifugation at $12,000 \times g$. Cell lysates were incubated with $20 \mu \mathrm{l}$ of protein A-agarose beads (Sigma) with $1 \mu \mathrm{g}$ of anti-FAK antibody (Santa Cruz Biotechnologies), or with $1 \mu \mathrm{g}$ of anti-cofilin antibody (Cytoskeleton) for $1 \mathrm{~h}$ at $4^{\circ} \mathrm{C}$. The beads were washed three times with ice-cold lysis buffer. Bound materials were eluted with SDS-PAGE sample buffer, resolved on $8-16 \%$ Tris-glycine gels, transferred onto nitrocellulose membranes, and immunoblotted with specific primary antibodies followed by incubation with corresponding secondary HRP-conjugated antibody and ECL detection. The secondary antibodies used were HRPconjugated goat anti-rabbit $(0.08 \mu \mathrm{g} / \mathrm{ml}$; Jackson ImmunoResearch),
HRP-conjugated donkey anti-mouse $(0.08 \mu \mathrm{g} / \mathrm{ml}$; Jackson ImmunoResearch), and HRP-conjugated donkey anti-goat $(0.04 \mu \mathrm{g} / \mathrm{ml}$; Jackson ImmunoResearch).

To inhibit ROCK, 14 DIV hippocampal neurons were preincubated with 10 or $75 \mu \mathrm{M}$ Y 27632 for 30 min and then treated with $4 \mu \mathrm{g} / \mathrm{ml}$ ephrin $\mathrm{B} 2-\mathrm{Fc}$ or $4 \mu \mathrm{g} / \mathrm{ml}$ control Fc for $20 \mathrm{~min}$ in the presence of ROCK inhibitor. Cell lysates were prepared as indicated above and subjected to immunoblotting against phospho-cofilin, cofilin, phospho-LIMK-1, and LIMK-1 using specific antibodies. The levels of phospho-cofilin or phospho-LIMK-1 were quantified by densitometry and normalized to total cofilin or LIMK-1 levels, respectively. Three independent experiments were performed for each condition. Statistical differences between Fc-treated and ephrinB2-Fc-treated samples were compared by Student's $t$ test.

\section{Results}

FAK depletion affects maintenance of mature dendritic spines in cultured hippocampal neurons

To determine the role of FAK in the maintenance of mature dendritic spines, we assessed the effects of FAK depletion on cultured hippocampal neurons at 14 and 21 DIV. Cells obtained from E15 hippocampi of conditional fak mutant mice, bearing loxP-flanked fak alleles, were cultured for 12 or 19 DIV to establish dendritic spines and synapses, then transfected with pEGFP (GFP) to visualize dendritic spine morphology and pPGK-Cre (Cre) to abolish FAK expression (Fig. $1 A-C$ ). FAK depletion was confirmed at 14 or 21 DIV by indirect immunofluorescence against FAK (Fig. 1A-C; supplemental Fig. 1, available at www. jneurosci.org as supplemental material). Cre-mediated deletion of fak led to reversion of mature spines to an immature phenotype in both 14 DIV and 21 DIV hippocampal neurons: dendritic protrusions were longer and more numerous in FAK-deficient neurons than in wild-type (WT) neurons (Fig. 1 D, F; supplemental Fig. 2, available at www.jneurosci.org as supplemental material). FAK-deficient neurons had fewer short mushroom-shaped and stubby protrusions $(<2.0 \mu \mathrm{m})$ and more long filopodia-like protrusions $(2.0-4.0 \mu \mathrm{m})$ than did WT neurons (Fig. $1 E$; supplemental Fig. 2, available at www.jneurosci.org as supplemental material). These significant effects of FAK depletion on dendritic protrusion number and length were suppressed by FAK overexpression (Fig. $1 D-F$ ), suggesting that FAK may regulate maintenance of mature dendritic spines in hippocampal neurons.

Dendritic spines accommodate the postsynaptic sites of excitatory synapses in hippocampal neurons, and changes in dendritic spine number and morphology directly correlate with synaptogenesis. To investigate whether changes in the number and length of dendritic protrusions triggered by Cre-mediated fak deletion also affected excitatory synapses in 14 DIV hippocampal neurons, we examined the dendritic spine morphology and the distribution of presynaptic and postsynaptic proteins, synaptophysin and PSD-95, respectively (Fig. 2A-F). FAK-deficient neurons exhibited longer dendritic spines with smaller heads than WT neurons (Fig. 2G,H). Analysis of dendritic spine morphology also revealed that FAK depletion induced an immature dendritic spine profile with a higher proportion of filopodia-like spines and fewer mushroom-shaped dendritic spines (Fig. $2 \mathrm{~J}$ ). Interestingly, filopodia-like long spines in FAK-deficient neurons occasionally formed branches and received multiple synaptophysin-positive presynaptic boutons (Fig. 2 I; supplemental Fig. 3, available at www.jneurosci.org as supplemental material). These effects of fak deletion on dendritic spines and synapses were reversed by FAK overexpression (Fig. 2C,F-J). The evidence from these studies suggests that FAK plays an important 
role in the maintenance of mature dendritic spines and synapses in hippocampal neurons.

\section{FAK depletion promotes actin} reorganization in mature dendritic spines and increases dendritic spine motility

Actin is the major component of the cytoskeleton that is accumulated in dendritic spines and is responsible for their formation, maintenance, and remodeling (Fischer et al., 1998; Matus, 2000; Carlisle and Kennedy, 2005). We next investigated whether the effects of FAK depletion on dendritic spine morphology are accompanied by actin reorganization. Polymerized F-actin, detected with rhodamine-coupled phalloidin, appeared as intense puncta along the dendritic shaft and was highly concentrated in the heads of mature dendritic spines of WT hippocampal neurons (Fig. 3A). However, in FAK-deficient neurons, thin dendritic spines contained linearly organized F-actin that appeared as hair-like extensions along the dendrite, while most $\mathrm{F}$-actin was found within the dendritic shaft (Fig. 3B). Quantitative analysis showed a reduction in the number and size of F-actin clusters in dendritic spines of FAK-deficient neurons (Fig. $3 D, E)$. These effects of fak deletion on actin organization in dendritic spines were rescued by overexpressing FAK (Fig. 3C$E)$. FAK depletion also enhanced dendritic spine motility in mature hippocampal neurons. While the dendritic spines of WT hippocampal neurons exhibited slow morphing movements, the spines of FAKdeficient neurons frequently protruded and retracted (supplemental Fig. 4, available at www.jneurosci.org as supplemental material). Our results suggest that actin reorganization due to FAK depletion drives a reversion of mature spines to an immature phenotype.

\section{FAK activation/phosphorylation is required for its effects on dendritic spines}

Taking into account that FAK functions are tightly linked to its phosphorylation state, we examined whether FAK activation is important to its effects on dendritic spines. FAK autophosphorylation on tyrosine 397 and assembly of the FAK-Src signaling complex have been shown to play an important role in its activation (Schaller et al., 1994). Our studies reveal that nonphosphorylatable FAK ${ }^{\mathrm{Y} 397 \mathrm{~F}}$ mutant failed to rescue the effects of fak deletion on dendritic spine length and morphology, indicating the significance of FAK phosphorylation on tyrosine 397 (Fig. 4A$D, G-I)$. In contrast, the overexpression of a constitutively active $\mathrm{FAK}^{\mathrm{Y} 397 \mathrm{E}}$ mutant restored mature dendritic spines in FAKdeficient hippocampal neurons. Finally, we investigated whether the dendritic spine-stabilizing effects of FAK depend on its ability
$12+2$ DIV hippocampal neurons
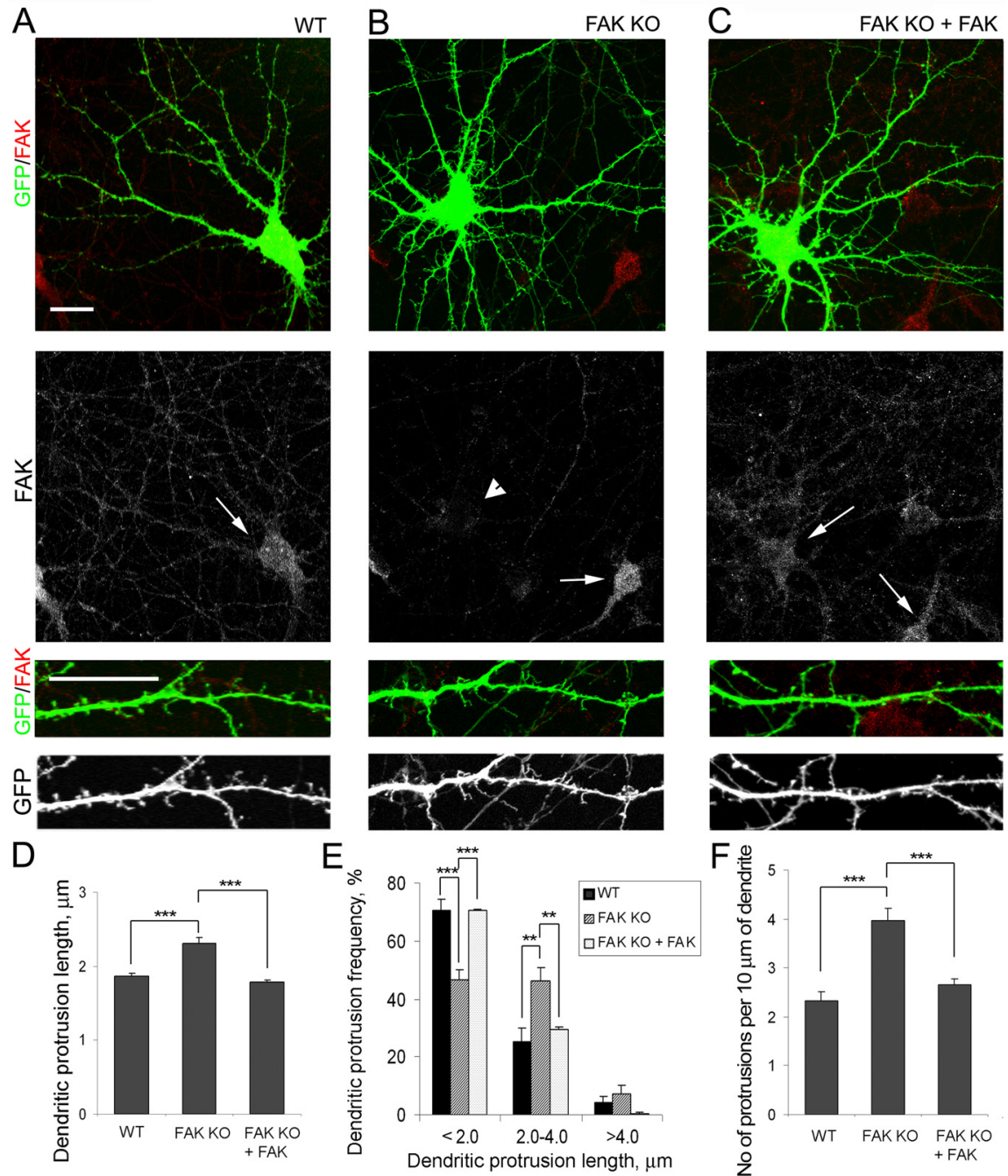

Figure 1. Disruption of FAK expression in 14 DIV hippocampal neurons promotes formation of new dendritic protrusions and elongation of existing ones. Neurons were obtained from E15 hippocampi of conditional fak mutant mice bearing loxP-flanked fak alees, transfected at 12 DIV, and processed for indirect immunofluorescence at 14 DIV. A-C, Confocal images of 14DIV hippocammology was observed with GFP fluorescence (green) and FAK expression was detected by immunostaining with anti-FAK (red). Arrows point to neurons with positive FAK immunoreactivity. A double GFP/Cre-expressing neuron with no FAK distribution of dendritic protrusion lengths: $<2 \mu \mathrm{m}, 2-4 \mu \mathrm{m}$, and $>4 \mu \mathrm{m}(\boldsymbol{E})$; and dendritic protrusion density in control and F**-deficient neurons $(\boldsymbol{F})$. Error bars indicate SEM $\left(n=200-400\right.$ dendritic protrusions from 10 neurons per group; ${ }^{* *} p<0.01$ $p<0.001)$. FAK-deficient neurons exhibited longer, more numerous filopodia-like protrusions than WT neurons. The effects of FAK depletion on dendritic protrusion number and length were suppressed by FAK overexpression.

to interact with Rho family GTPase regulatory proteins by mutating lysine 1034 to serine, or proline 878 to alanine in the focal adhesion targeting (FAT) domain of FAK. Indeed, FAK ${ }^{\text {L1034S }}$ and $\mathrm{FAK}^{\mathrm{P} 878 \mathrm{~A}}$ mutants were unable to restore mature dendritic spine morphology in FAK-deficient hippocampal neurons (Fig. 4E, F). Altogether, these data provide further evidence that FAK activity and the FAT domain are important for the maintenance of mature dendritic spines and synapses.

\section{FAK acts downstream of EphB receptors in hippocampal neurons to maintain mature dendritic spines}

As FAK activity is an important factor in dendritic spine and synapse maturation, we next investigated whether FAK acts downstream of EphB receptors, contributing to the stability of 

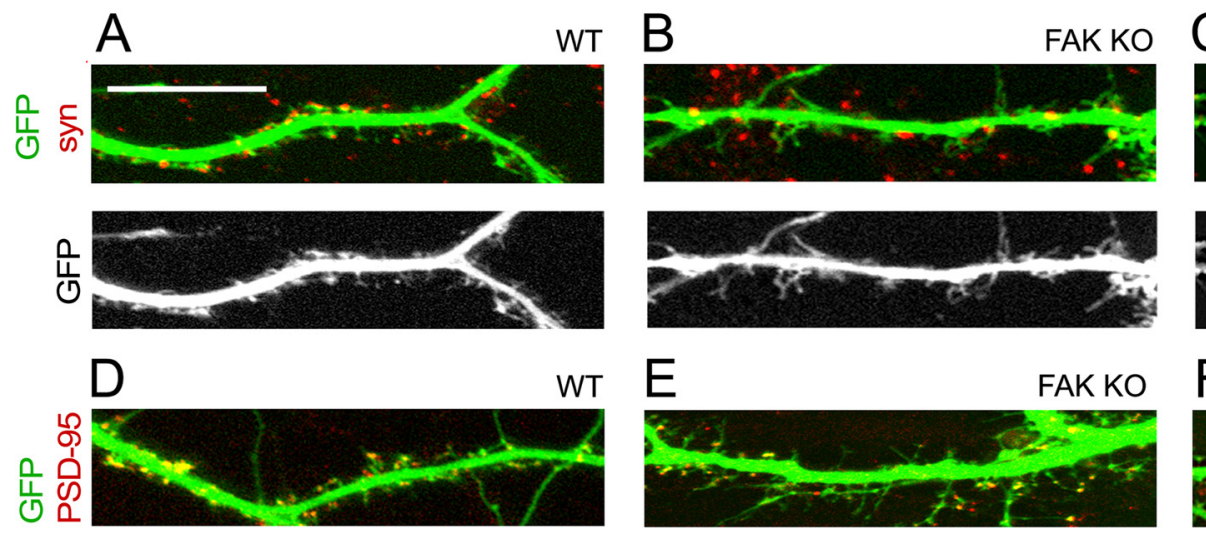

$12+2$ DIV hippocampal neurons
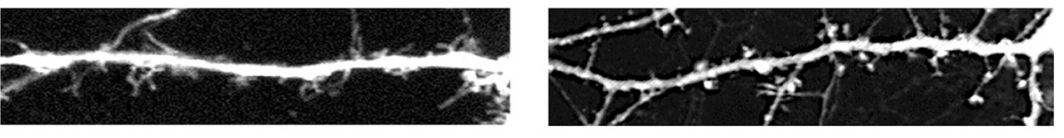

E

FAK KO

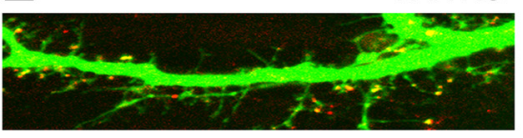

$\mathrm{F}$

FAK KO + FAK
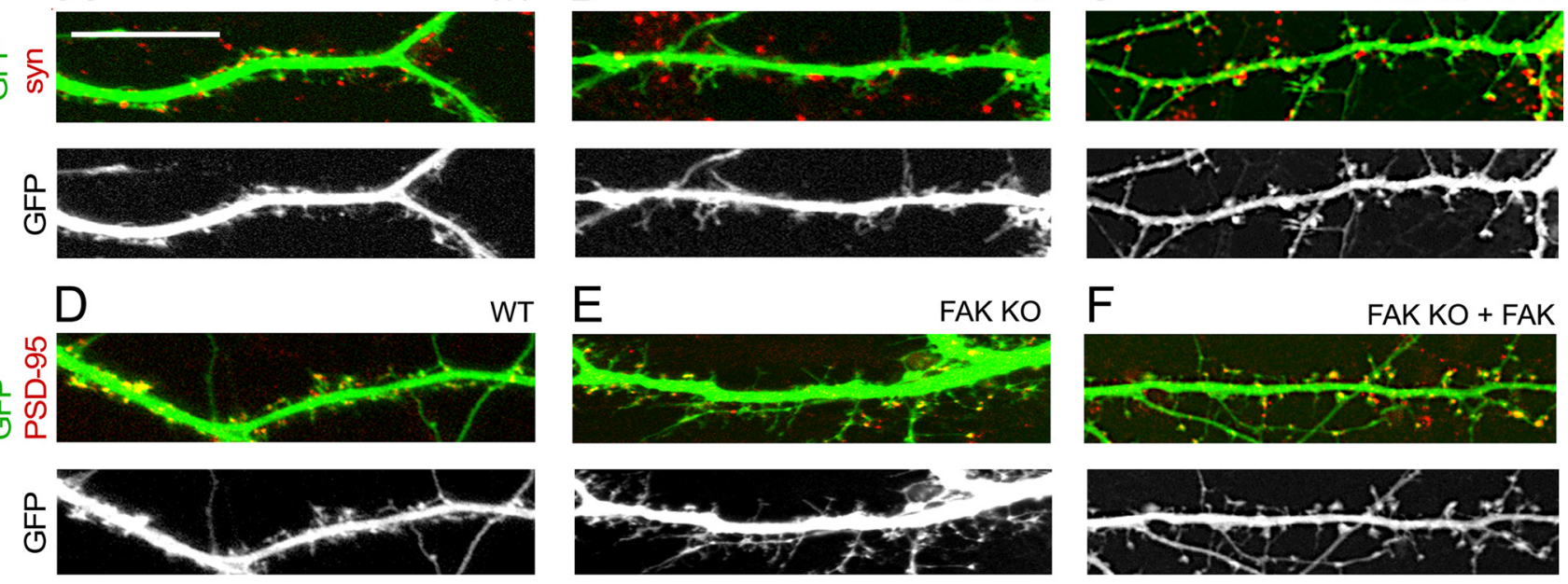

G

$\mathrm{H}$
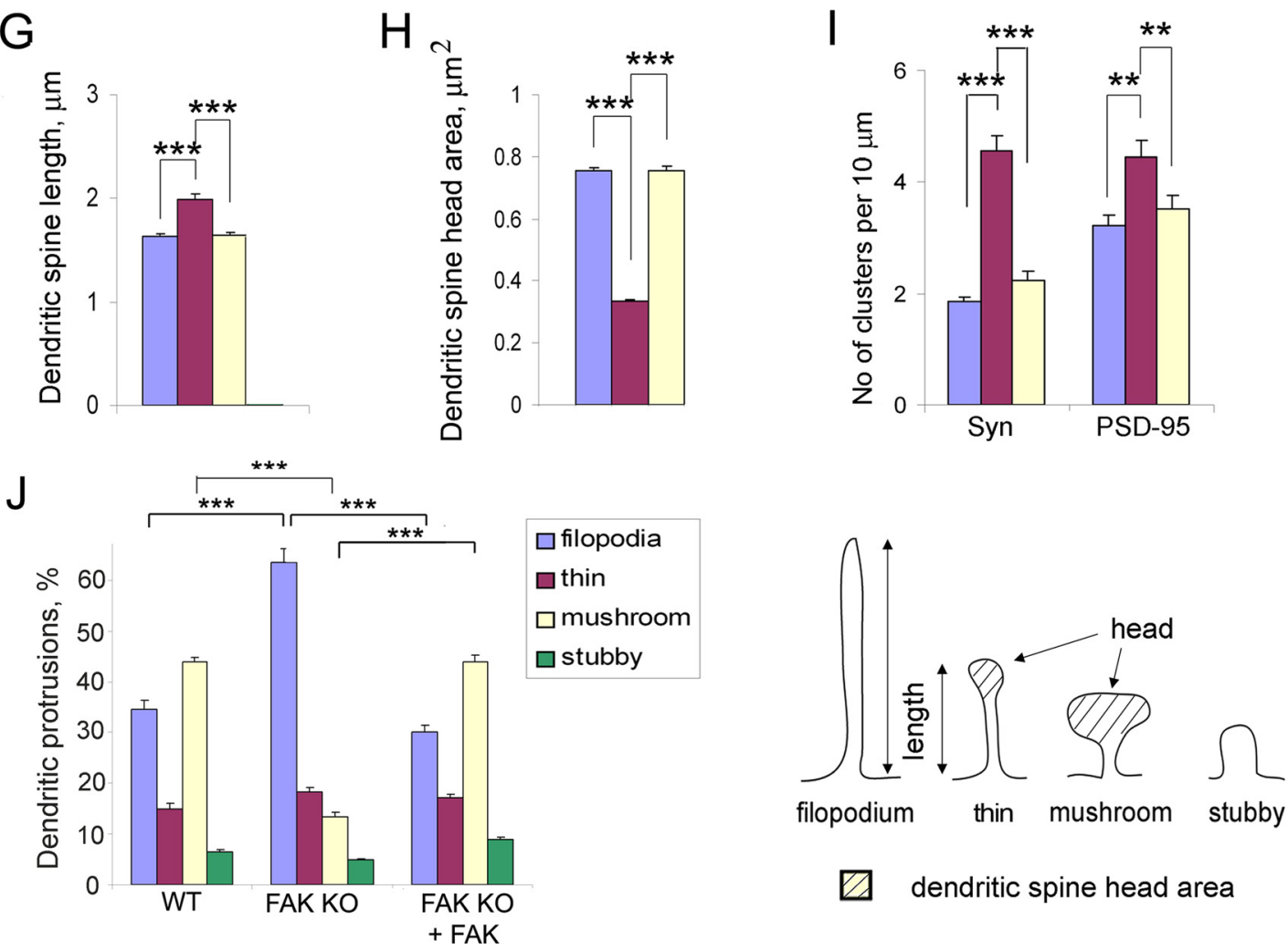

$\square$ dendritic spine head area

Figure 2. FAK depletion affects dendritic spine morphology and synapses. $\boldsymbol{A}-\boldsymbol{F}$, Confocal images of 14 DIV hippocampal neurons expressing GFP alone (WT) $(\boldsymbol{A}, \boldsymbol{D})$, GFP and (re (FAK K0) (B, E), or GFP, (re, and FAK (FAK KO + FAK) (C, F). Neurons were obtained from E15 hippocampi of conditional fak mutant mice bearing loxP-flanked fak alleles, transfected at 12 DIV, and processed for indirect immunofluorescence at 14 DIV. Dendritic spine morphology was observed with GFP fluorescence (green), presynaptic boutons were labeled by immunostaining for the presynaptic vesicle marker synaptophysin (red, $\boldsymbol{A}-\boldsymbol{C}$ ), and postsynaptic sites of excitatory synapses were labeled by immunostaining for PSD-95 (red, $\boldsymbol{D}-\boldsymbol{F}$ ). Scale bars, $10 \mu \mathrm{m}$. G-J, Quantitative analysis of dendritic spine lengths $(\boldsymbol{G})$, dendritic spine head areas $(\boldsymbol{H})$, number of synaptophysin- and PSD95-positive puncta $(\boldsymbol{I})$, and dendritic spine morphology $(\boldsymbol{J})$. Error bars indicate SEM $(n=200-400$ dendritic spines from 10 neurons per group; ${ }^{* * *} p<0.001$ ). FAK depletion induces immature dendritic spine profiles in cultured hippocampal neurons. FAK-deficient neurons exhibit more filopodia-like thin spines and less mushroom-shaped dendritic spines. FAK depletion also promotes new filopodia formation, while the number of dendritic spines remains unchanged. These effects of fak deletion on dendritic spine morphology were suppressed by overexpression of FAK.

mature dendritic spines and synapses in hippocampal neurons. We found that similar to young 7 DIV hippocampal neurons, the activation of EphB2 receptor with its soluble ephrinB2-Fc ligand induced long-lasting phosphorylation of FAK on tyrosine 397, a known mechanism of FAK activation, as well as its association with the EphB2 receptor in mature 14 DIV hippocampal neurons (Fig. $5 A, B$ ). Treatment of these neurons with ephrinB2-Fc for 5 min resulted in a robust increase in the phosphorylation of FAK that remained high at 15 and $30 \mathrm{~min}$, and assembly of a FAK/Src/ paxillin complex. Interestingly, the recruitment and activation of FAK that was triggered by EphB2 receptor activation interfered with the association of FAK with integrins, well known regulators of FAK activity. Ephrin-B2-induced activation of EphB2 receptors led to a prolonged dissociation of FAK from $\beta 3$ integrins, 
suggesting a competition between EphB receptors and integrins for control over FAK in hippocampal neurons (Fig. 5A,B).

To inhibit forward signaling of the EphB2 receptor, we then cultured hippocampal neurons for 12 or 19 DIV to develop dendritic spines and synapses, and used transfection to express dnEphB2. Dendritic spines were identified as dendritic protrusions with adjacent synaptophysinpositive presynaptic boutons and positive PSD-95 immunoreactivity. Overexpression of dnEphB2 significantly changed dendritic spine length and morphology toward an immature spine profile, suggesting that EphB receptor forward signaling is also required for the maintenance of mature dendritic spine morphology in cultured hippocampal neurons (Fig. 6A, B,D-G). These changes in dendritic spine morphology, number, and length induced by the inhibition of EphB receptor forward signaling resembled the effects of fak deletion in cultured hippocampal neurons. Moreover, overexpression of constitutively active $\mathrm{FAK}^{\mathrm{Y} 397 \mathrm{E}}$, but not nonphosphorylatable FAK ${ }^{\mathrm{Y} 397 \mathrm{~F}}$, reversed the effects of dnEphB2 on spine morphology, length, and number (Fig. 6C-G), further supporting our observation that FAK activation plays a critical role in EphB receptor signaling in dendritic spines. These studies demonstrate that FAK acts downstream of EphB receptors in mature hippocampal neurons and constitutively active FAK ${ }^{\mathrm{Y} 397 \mathrm{E}}$ restores mature dendritic spines disrupted by inhibiting EphB receptor activity.

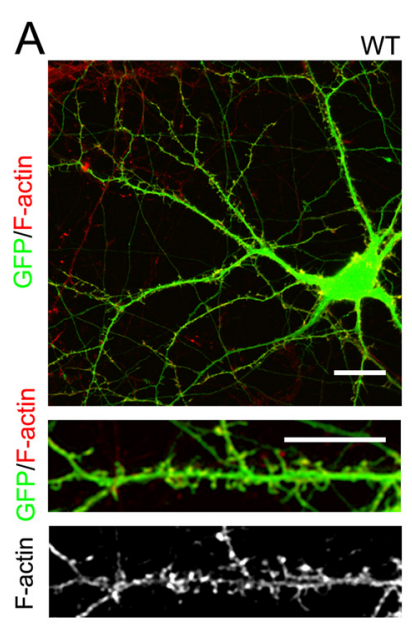

12 + 2 DIV hippocampal neurons
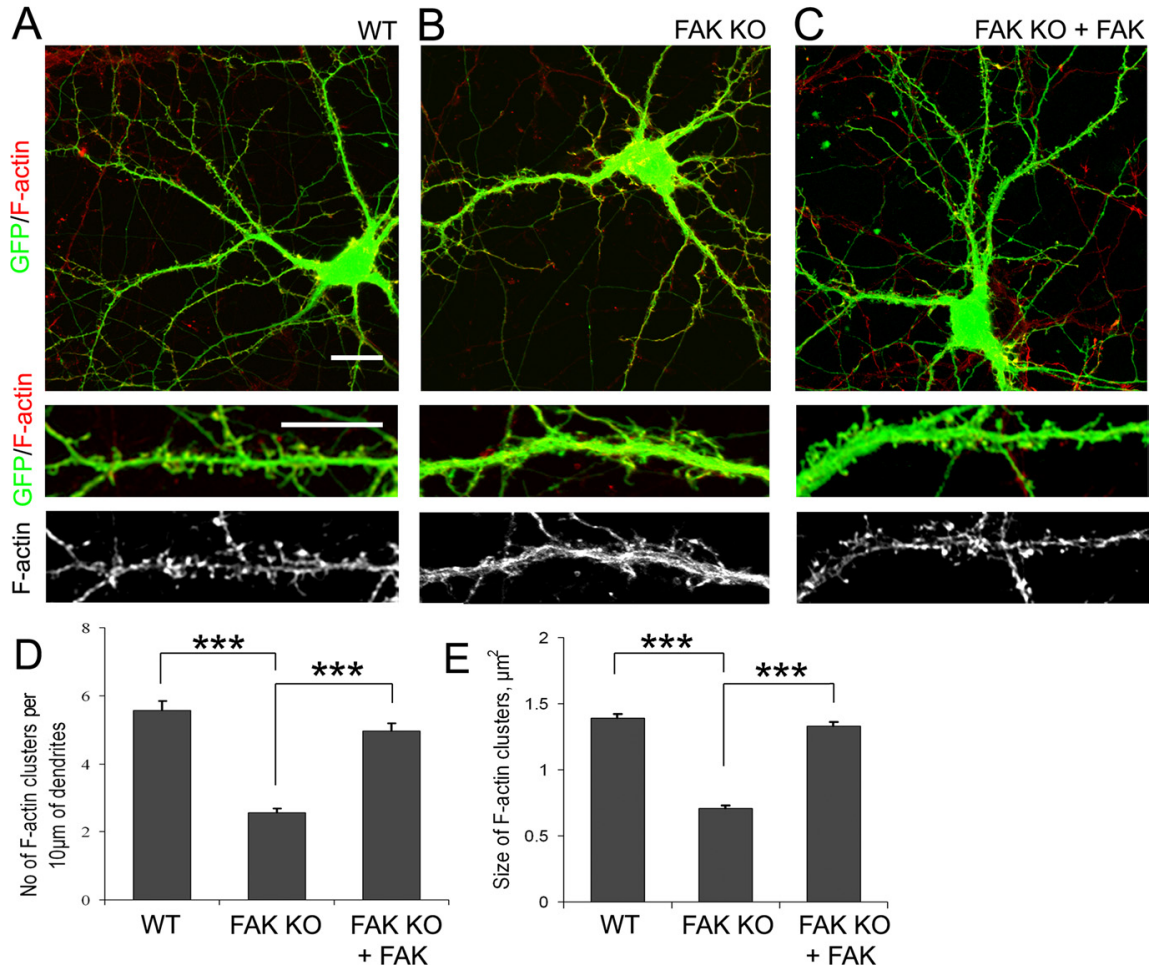

Figure 3. FAK depletion induces actin reorganization in 14 DIV hippocampal neurons. $\boldsymbol{A}-\boldsymbol{C}$, Confocal images of 14 DIV hippocampal neurons expressing GFP alone (WT) (A), GFP and Cre (FAK KO) (B), or GFP, Cre, and FAK (FAK KO + FAK) (C). Neurons were obtained from E15 hippocampi of conditional fak mutant mice bearing loxP-flanked fak alleles, transfected at 12 DIV, and processed for indirect immunofluorescence at 14 DIV. Dendritic spine morphology was observed with GFP fluorescence (green). Polymerized F-actin was detected in dendritic spines with rhodamine-coupled phalloidin (red). Scale bars, $10 \mu \mathrm{m}$. D, E, Quantitative analysis of numbers $(\boldsymbol{D})$ and sizes $(\boldsymbol{E})$ of F-actin clusters in control neurons, FAK KO neurons, or FAK KO neurons overexpressing FAK. Data represent the average number of F-actin clusters per $10 \mu \mathrm{m}$ of dendrite $(\boldsymbol{D})$ or average size of F-actin clusters $(\boldsymbol{E})$. Error bars indicate SEM ( $n=250-500 \mathrm{~F}$-actin clusters from 10 neurons per group; $\left.{ }^{* * *} p<0.001\right)$. FAK-deficient neurons show reductions in number and size of F-actin clusters in dendritic spines compared with control neurons. The effects are rescued by overexpression of FAK.

\section{EphB2 receptors induce cofilin}

\section{phosphorylation in cultured hippocampal neurons}

Our results show that FAK acts downstream of EphB receptors and may promote dendritic spine stability through Rho family GTPase regulatory proteins. Moreover, our previous studies demonstrated that EphB2 receptor activation in hippocampal neurons upregulates RhoA activity (Moeller et al., 2006). Altogether, these findings suggest that EphB2-mediated dendritic spine stabilization may rely on the ability of FAK to activate the RhoA-LIMK-1 pathway that works to suppress cofilin activity and discourage cofilin-mediated dendritic spine remodeling.

To investigate this hypothesis, we first assessed whether EphB2 receptor regulates cofilin activity. Cofilin induces F-actin disassembly and reorganization through its severing activity, which can be downregulated by phosphorylation of serine-3 (Bamburg, 1999). To investigate whether EphB receptor activation regulates cofilin activity, we examined cofilin phosphorylation following EphB2 receptor activation in 14 DIV hippocampal neurons. Western blot revealed a higher level of cofilin phosphorylation in neurons treated with ephrin-B2-Fc than in neurons treated with control Fc $(p<0.01)$ (Fig. $7 A, B)$. Activation of EphB receptors also increased LIMK-1 activation in ephrin-B2Fc-treated hippocampal neurons compared with Fc-treated controls as demonstrated by increased level of LIMK-1 phosphorylation by Western blot $(p<0.05)$ (Fig. 7C). Moreover, ephrinB2-induced cofilin phosphorylation was significantly inhibited with a specific inhibitor, Y27632, of Rho-associated kinase (ROCK) (Fig. $7 A, B$ ). These results demonstrate that cofilin activity is controlled by EphB receptors at least partially through the regulation of ROCK and LIMK activities, and suggest that downregulation of cofilin activity by LIMK-mediated phosphorylation may be responsible for maintaining mature dendritic spines.

\section{FAK-mediated regulation of mature dendritic spine} morphology and cofilin phosphorylation depends on its activation/phosphorylation and its ability to interact with regulators of Rho family GTPases

We have analyzed whether FAK overexpression can regulate dendritic spine morphology, cofilin phosphorylation, and the cofilin/phospho-cofilin ratio in dendrites of cultured mouse hippocampal neurons. Our studies demonstrate that overexpression of FAK significantly increased cofilin phosphorylation $(p<$ $0.05)$ and reduced the cofilin/phospho-cofilin ratio $(p<0.05)$ in dendrites of cultured mouse hippocampal neurons compared with control GFP-expressing neurons (Fig. 8). Moreover, overexpression of constitutively active FAK ${ }^{\mathrm{Y} 397 \mathrm{E}}$ further increased cofilin phosphorylation and significantly decreased the cofilin/ phospho-cofilin ratio compared with control GFP-expressing neurons $(p<0.001)$. In addition, the overexpression of FAK or FAK $^{\mathrm{Y} 397 \mathrm{E}}$ also increased the size of dendritic spine heads compared with those in control GFP-expressing neurons $(p<0.05$ 

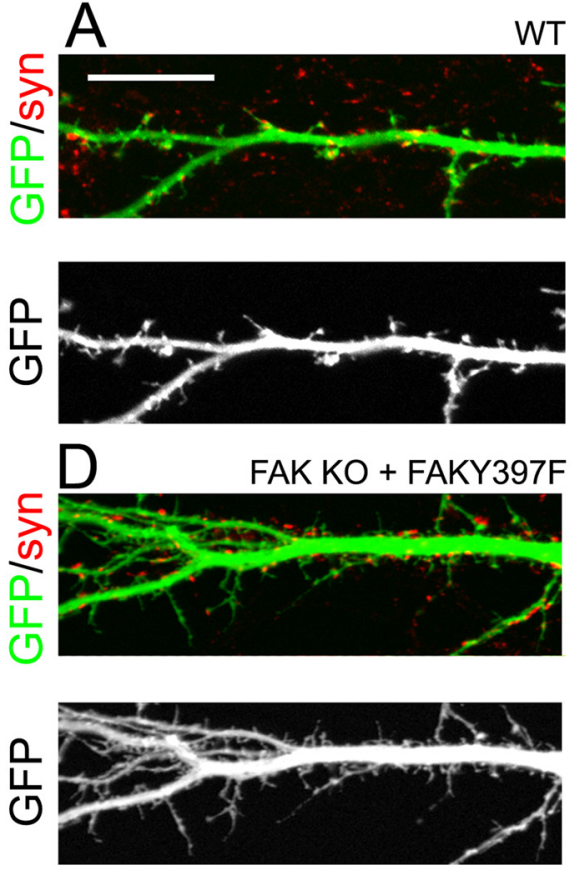

G

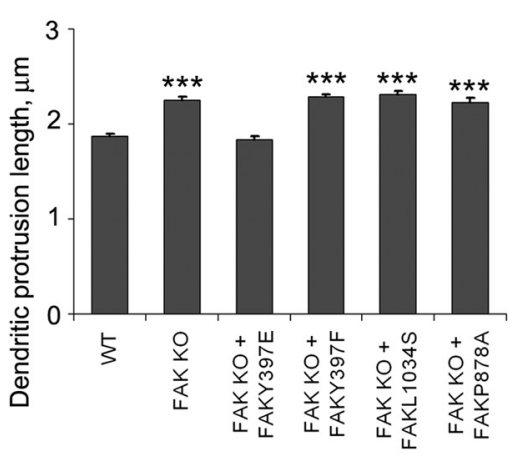

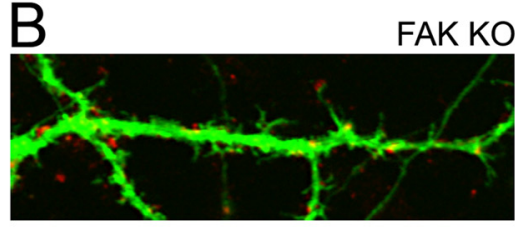
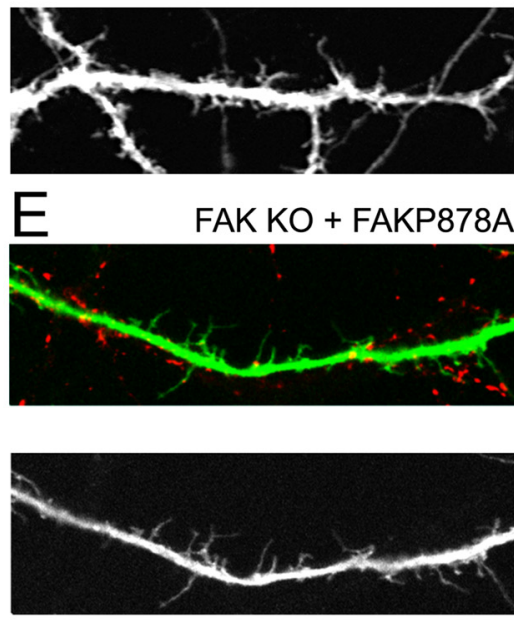

$\mathrm{H}$

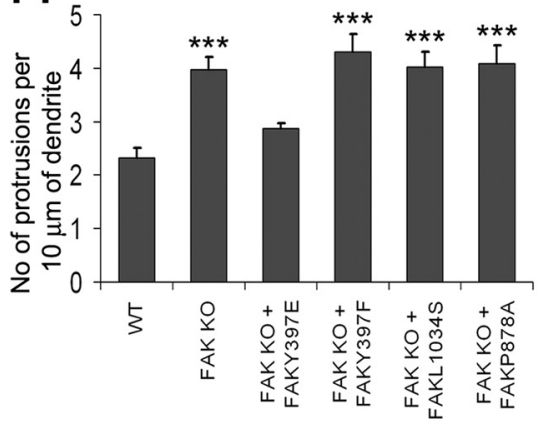

$12+2$ DIV hippocampal neurons
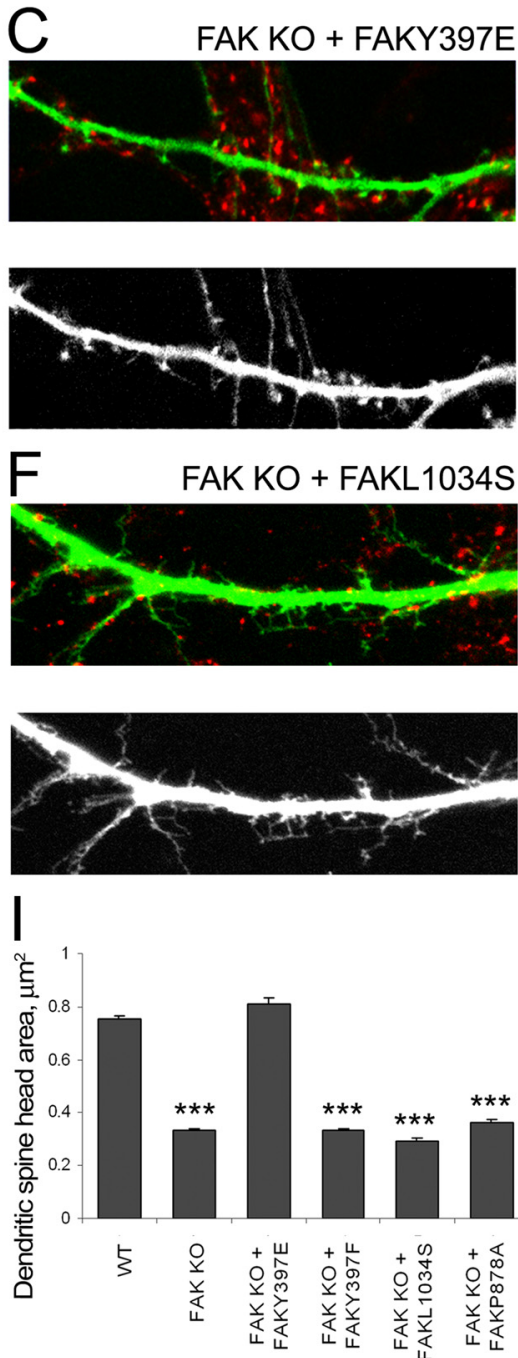

Figure 4. FAK activation/phosphorylation and its ability to interact with regulators of Rho family GTPases are required for its effects on dendritic spines. $\boldsymbol{A}-\boldsymbol{F}$, Confocal images of the dendrites of 14 DIV hippocampal neurons expressing GFP alone (WT) (A), GFP and Cre (FAK KO) (B), GFP, Cre, and FAK ${ }^{\text {Y397E }}$ (FAK KO + FAKY397E) (C), GFP, Cre, and FAK ${ }^{\text {Y397F }}$ (FAK KO + FAKY397F) (D), GFP, Cre, and FAK ${ }^{\text {P878A }}$ (FAK KO + FAKP878A) (E), or GFP, Cre, and FAK ${ }^{\text {L1034S }}$ (FAK KO + FAKL1034S) ( $\boldsymbol{F}$ ). Neurons were obtained from E15 hippocampi of conditional fak mutant mice bearing loxP-flanked fak alleles, transfected at 12 DIV, and processed for indirect immunofluorescence at 14 DIV. Dendritic spine morphology was observed with GFP fluorescence (green), presynaptic boutons were labeled by immunostaining for the presynaptic vesicle marker synaptophysin (red, $\boldsymbol{A}-\boldsymbol{F}$ ). Scale bars, $10 \mu \mathrm{m} . \mathbf{G}-\boldsymbol{I}$, Quantification of dendritic protrusion lengths (G), dendritic protrusion densities $(\boldsymbol{H})$, and dendritic spine head area $(\boldsymbol{I})$ in control and FAK-deficient neurons. Error bars indicate SEM $\left(n=500-700\right.$ dendritic protrusions from 10 neurons per group; $\left.{ }^{* * *} p<0.001\right)$. Constitutively active $\mathrm{FAK}^{\mathrm{Y} 397 \mathrm{E}}$, but not inactive FAK ${ }^{\mathrm{Y} 397 \mathrm{~F}}$ mutant, restored mature dendritic spines in FAK-deficient hippocampal neurons.

and $p<0.01$, respectively), shifting the spine head-to-length ratio toward a more mature spine phenotype. However, the overexpression of either the FAK ${ }^{\mathrm{L} 1034 \mathrm{~S}}$ mutant, which is unable to interact with regulators of Rho family GTPases, or the nonphosphorylatable $\mathrm{FAK}^{\mathrm{Y} 397 \mathrm{~F}}$ failed to induce cofilin phosphorylation or to reduce cofilin/phospho-cofilin ratio compared with control GFP-expressing neurons. The levels of phospho-cofilin in the dendrites of neurons expressing FAK $^{\mathrm{L} 1034 \mathrm{~S}}$ or FAK ${ }^{\mathrm{Y} 397 \mathrm{~F}}$ were significantly lower than in neurons overexpressing FAK or constitutively active $\mathrm{FAK}^{\mathrm{Y} 397 \mathrm{E}}$ ( $p<0.05$ and $p<0.01$, respectively). Furthermore, spine head size for neurons expressing FAK ${ }^{\mathrm{L} 1034 \mathrm{~S}}$ or FAK ${ }^{\mathrm{Y} 397 \mathrm{~F}}$ were significantly smaller than control neurons and those over-expressing FAK or FAK ${ }^{\mathrm{Y} 397 \mathrm{E}}(p<0.001)$, shifting the spine head-to-length ratio toward an immature spine phenotype. Our observations suggest that FAK activation on Y397 and its ability to interact with regulators of Rho family GTPases are in- volved in the regulation of cofilin phosphorylation and dendritic spine morphology in mature hippocampal neurons.

The constitutively active cofilin ${ }^{\mathrm{S}}{ }^{\mathrm{A}}$, but not inactive phosphomimetic cofilin ${ }^{\mathrm{S} D}$ or wt-cofilin, induces immature dendritic spines

As a prelude to determining the role of cofilin activity in EphB2mediated stabilization of dendritic spines, we analyzed the overall effects of constitutively active cofilin ${ }^{\mathrm{S} 3 \mathrm{~A}}$ or inactive cofilin ${ }^{\mathrm{S} 3 \mathrm{D}}$ mutants on dendritic spine morphology. The overexpression of the nonphosphorylatable cofilin ${ }^{\text {S3A }}$, but not the phosphomimetic cofilin ${ }^{\mathrm{S} 3 \mathrm{D}}$ or wt-cofilin, induced remodeling of mature dendritic spines and the extension of new filopodia in 14 DIV hippocampal neurons (Fig. 9). Neurons expressing nonphosphorylatable cofilin ${ }^{\mathrm{S} 3 \mathrm{~A}}$ had dendritic spines that were longer and with smaller heads than neurons expressing inactive cofilin ${ }^{\mathrm{S} 3 \mathrm{D}}$ or 
wt-cofilin (Fig. 9E-H). Interestingly, wtcofilin accumulated in mature spines (supplemental Fig. 4, available at www. jneurosci.org as supplemental material), but did not affect the size of dendritic spine heads (Fig. 9H), suggesting the existence of a signaling mechanism that suppresses cofilin activity in mature spines. In addition, the overexpression of inactive cofilin $^{\text {S3D }}$ significantly decreased the length of dendritic spines compared with those in control neurons or neurons expressing active cofilin ${ }^{\mathrm{S} 3 \mathrm{~A}}$, shifting the spine head-to-length ratio toward a more mature spine phenotype. The ability of cofilin $^{\mathrm{S} 3 \mathrm{D}}$ to promote mature dendritic spines suggests that it may act on endogenous cofilin in a dominant-negative manner, probably by competing for binding to phosphatases that dephosphorylate and thereby activate cofilin. These results demonstrate that only nonphosphorylatable, constitutively active cofilin ${ }^{\mathrm{S} 3 \mathrm{~A}}$ prompted the transformation of mature mushroomshaped spines into thin immature spines with smaller heads, indicating that cofilin activity is downregulated in mature dendritic spines by phosphorylation.

\section{Phosphomimetic cofilin ${ }^{\text {S3D }}$ restores mature dendritic spines disrupted by inhibiting EphB receptor activity or FAK depletion}

To determine whether EphB signaling promotes dendritic spine stability through cofilin inhibition by phosphorylation, we disrupted this pathway at the level of either EphB2 receptor activity or FAK expression. We then assessed the effects of constitutively active cofilin ${ }^{\mathrm{S} 3 \mathrm{~A}}$ or phosphomimetic cofilin ${ }^{\mathrm{S} 3 \mathrm{D}}$ mutants on dendritic spine morphology. The inhibition of EphB receptor forward signaling by overexpression of dnEphB2 significantly changed dendritic spine length and morphology toward an immature spine profile (Figs. 6, 10A-H). These changes were reversed by the overexpression of phosphomimetic cofilin ${ }^{\mathrm{S} D}$, but not nonphosphorylatable cofilin ${ }^{\mathrm{S} 3 \mathrm{~A}}$, suggesting that the regulation of cofilin activity plays an important role in EphB2 receptormediated dendritic spine maturation (Fig. 10A-H). Similar effects were seen with the overexpression of these cofilin mutants in FAK-deficient neurons (Fig. 10I-P). The disruption of mature spine phenotype seen in FAK-deficient neurons was reversed by overexpressing phosphomimetic cofilin ${ }^{\mathrm{S} D}$, but not nonphosphorylatable cofilin ${ }^{\mathrm{S} A}$. These studies suggest that the EphB2FAK signaling pathway promotes the stabilization of mature dendritic spines and synapses through the regulation of cofilin activity by phosphorylation.

\section{Discussion}

Our studies reveal that nonreceptor tyrosine kinase FAK plays an important role in the maintenance of mature dendritic spines in cultured hippocampal neurons. Cre-mediated knock-out of loxP-flanked $f a k$ in dendrites of mature hippocampal neurons induced remodeling of dendritic spines and synapses. The effects of FAK deletion on dendritic spine morphology and synapses were reversed by the overexpression of wild-type FAK and constitutively active $\mathrm{FAK}^{\mathrm{Y} 397 \mathrm{E}}$, but not FAK ${ }^{\mathrm{Y} 397 \mathrm{~F}}$, indicating a signif- icance of FAK activation in the maintenance of mature dendritic spines. FAK is typically activated during assembly of integrinmediated focal adhesions by phosphorylation on tyrosine 397, which in turn creates a binding site for other signaling proteins that link FAK to downstream signaling pathways and actin cytoskeleton (Schaller et al., 1994; Parsons, 2003; Mitra et al., 2005). In addition to integrins, several other cell surface receptors and their ligands were shown to regulate FAK activity, including the DCC receptor, netrin, Eph receptors, and ephrins (Cowan and Henkemeyer, 2001; Miao et al., 2001; Li et al., 2004; Ren et al., 2004; Nikolopoulos and Giancotti, 2005; Moeller et al., 2006). Our previous studies demonstrated that EphB2 activation in 7 DIV hippocampal neurons induces FAK activation and assembly of a FAK/Src complex that contributes to the formation of dendritic spines and dendritic filopodia shortening/elimination (Moeller et al., 2006). Here we investigated whether EphB receptors also regulate FAK activity in mature dendritic spines. When EphB receptor forward signaling was inhibited by the overexpression of dnEphB2 in mature 14-21 DIV hippocampal neurons, we saw a shift toward an immature spine morphology that was reversed by the overexpression of constitutively active FAK ${ }^{\mathrm{Y} 397 \mathrm{E}}$, but not nonphosphorylatable FAK ${ }^{\mathrm{Y} 397 \mathrm{~F}}$. The role of EphB2 receptor in the maintenance of mature dendritic spines has been also demonstrated in cortical neuron cultures (Kayser et al., 2008). Our results further confirm this observation in hippocampal neuron cultures and show that FAK acts downstream of the EphB receptors and FAK activation plays an important role in EphB2 signaling to maintain mature dendritic spines and synapses.

Next, we investigated the mechanism by which the EphB2FAK pathway promotes dendritic spine stabilization. Our previous studies demonstrated that EphB-mediated activation of RhoA in hippocampal neurons depends on FAK activity (Moeller et al., 2006), suggesting that FAK may direct activity of actin- 


\section{2 + 2 DIV hippocampal neurons}

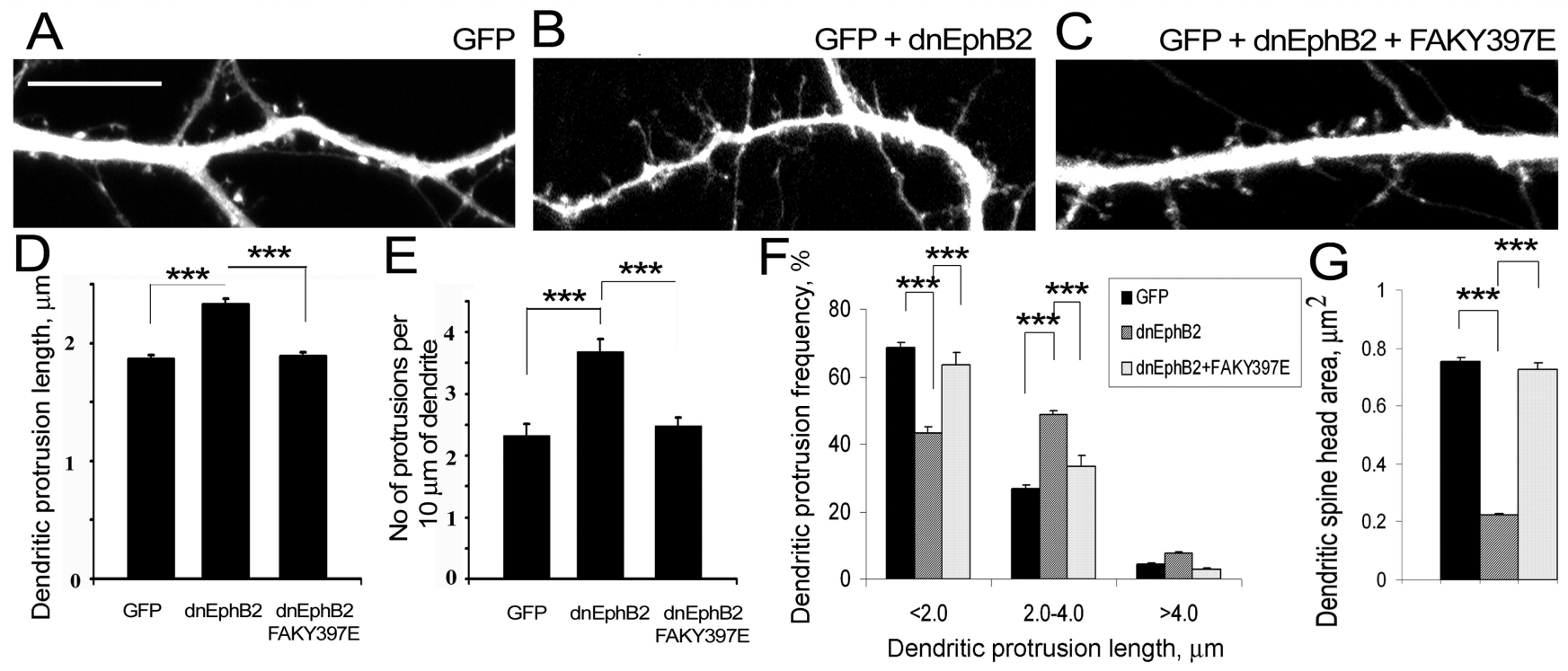

Figure 6. Constitutively active FAK ${ }^{\mathrm{Y} 397 \mathrm{E}}$ restores mature dendritic spine morphology disrupted by the inhibition of EphB2 receptor activity. $\boldsymbol{A}-\boldsymbol{C}$, Confocal images of dendrites of 14 DIV hippocampal neurons expressing GFP alone (GFP) (A), GFP and dnEphB2 ${ }^{\text {K662R }}$ (GFP $+\operatorname{dnEphB2)}(\boldsymbol{B})$, or GFP, dnEphB2 ${ }^{\mathrm{K} 662 \mathrm{R}}$, and FAK ${ }^{\mathrm{Y} 397 \mathrm{E}}$ (GFP + dnEphB2 + FAKY397E) (C). Neurons were obtained from E15 hippocampi of wt mice, transfected at 12 DIV, and processed for indirect immunofluorescence at 14 DIV. Scale bars, $10 \mu \mathrm{m}$. $\boldsymbol{D}-\mathbf{G}$, Quantification of dendritic spine length (D); dendritic spine density $(\boldsymbol{E})$; distribution of dendritic protrusion lengths: $<2 \mu \mathrm{m}, 2-4 \mu \mathrm{m}$, and $>4 \mu \mathrm{m}(\boldsymbol{F})$; and dendritic spine head area ( $\boldsymbol{G}$ ). Error bars indicate $S E M(n=500$ dendritic protrusions from 10 neurons per group; $\left.{ }^{* * *} p<0.001\right)$. While hippocampal neurons expressing dnEphB2 developed elongated dendritic spines and filopodia, the neurons expressing dnEphB2 together with constitutively active FAK ${ }^{\text {Y397E }}$ exhibit mature mushroom-like dendritic spines similar to control GFP-transfected neurons.

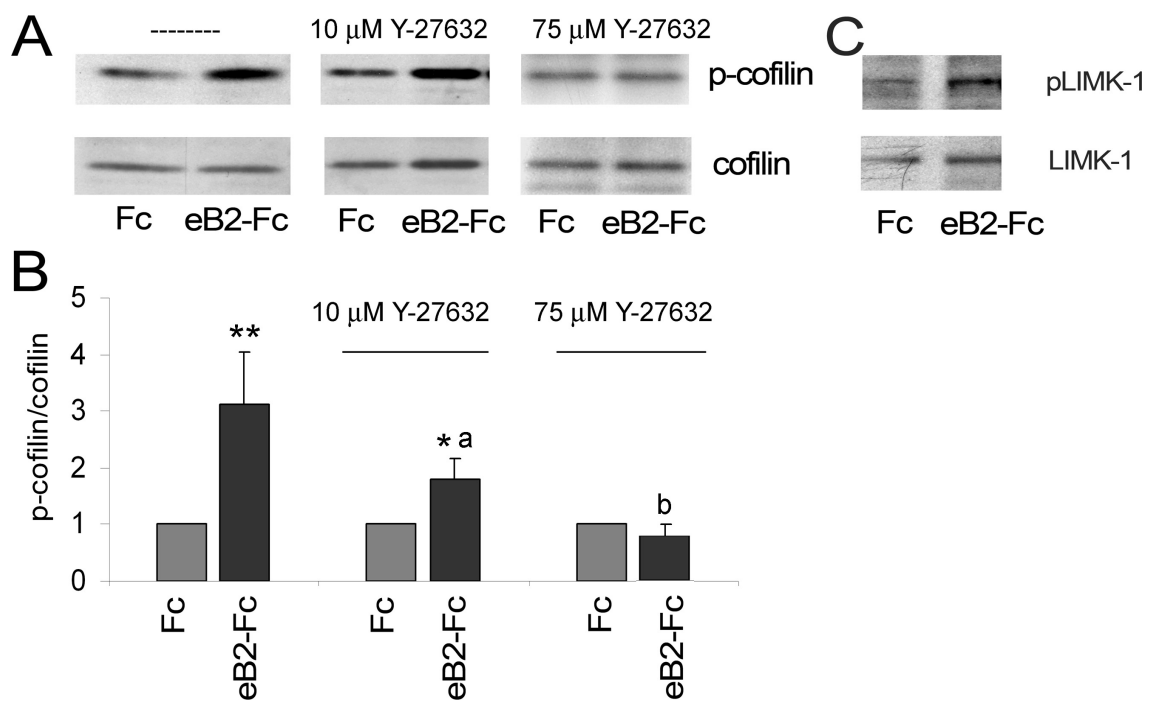

Figure 7. The EphB2 receptor induces cofilin phosphorylation in cultured hippocampal neurons. $\boldsymbol{A}, \boldsymbol{C}$, Hippocampal neurons (14 DIV) were treated with ephrin B2-Fc to activate EphB receptors or control Fc for 15 min with or without ROCK inhibitor Y27632 at 10 or $75 \mu \mathrm{m}$. Cell lysates were subjected to immunoblotting with anti-phospho-cofilin $(\boldsymbol{A})$ or anti-phospho-LIMK-1/2 (C) antibodies. The blots were stripped and reprobed against total cofilin or LIMK-1. $\boldsymbol{B}$, The levels of phospho-cofilin were quantified by densitometry and normalized to total cofilin. Experimental values represent mean $\pm S D(n=3)$. Values significantly different in ephrinB2-Fc-treated samples compared with control Fc samples are indicated by asterisks $\left({ }^{*} p<0.05 ;{ }^{* *} p<0.01\right)$. Cofilin phosphorylation levels were significantly lower in samples treated with ephrinB2-Fc in presence of $10 \mu \mathrm{M} Y 27632$ ( ${ }^{\mathrm{a}} p<0.05$ ) or $75 \mu \mathrm{M} Y 27632$ ( ${ }^{\mathrm{b}} p<0.01$ ) than in samples treated with ephrinB2-Fc alone. EphB2 receptor activation with preclustered ephrin B2-Fc led to increased levels of phosphorylated cofilin that was inhibited with ROCK inhibitor Y27632.

regulating proteins in dendritic spines. FAK is known to associate with regulators of Rho family GTPases through its FAT domain and to regulate their activities in non-neuronal cells (Hildebrand et al., 1996; Zhai et al., 2003; Mitra et al., 2005; Torsoni et al., 2005; Iwanicki et al., 2008). In neurons FAK was shown to control axonal branching in part by regulating Rho family GTPases as the overexpression of FAK ${ }^{\text {L1034S }}$ and $\mathrm{FAK}^{\mathrm{P} 878 \mathrm{~A}}$ mutants, which are unable to interact with regulators of Rho family GTPases, failed to rescue the axonal arborization phenotype observed in FAK-deficient neurons (Rico et al., 2004). Our studies demonstrate that FAK ${ }^{\mathrm{L} 1034 \mathrm{~S}}$ and FAK ${ }^{\mathrm{P} 878 \mathrm{~A}}$ mutants were also unable to restore mature dendritic spines in FAK-deficient hippocampal neurons. Therefore, it is possible that FAK also regulates actin organization in dendritic spines through Rho family GTPases.

Members of Rho family GTPases, such as RhoA, Cdc42, and Rac, are essential regulators of actin polymerization (Luo, 2002). Rho-related signaling have been linked to mental retardation (van Galen and Ramakers, 2005), and have been shown to regulate the formation of dendritic spines (Govek et al., 2004; Irie et al., 2005; Zhang et al., 2005; Tolias et al., 2007; Xie et al., 2007; Saneyoshi et al., 2008; Wegner et al., 2008). Rac1, Cdc42, and RhoA can also promote activation of LIMK-1 through Pak and ROCK, respectively (Yang et al., 1998; Edwards et al., 1999; Maekawa et al., 1999); and Pak1 and ROCK2 have been demonstrated to regulate dendritic spine properties and synaptic density through LIMK-mediated regulation of cofilin activity (Asrar et al., 2009; Zhou et al., 2009). LIMK-1 is a nonreceptor serine/threonine kinase that inhibits F-actin severing protein cofilin by serine 3 phosphorylation (Arber et al., 1998; Sumi et al., 


\section{$12+2$ DIV hippocampal neurons}
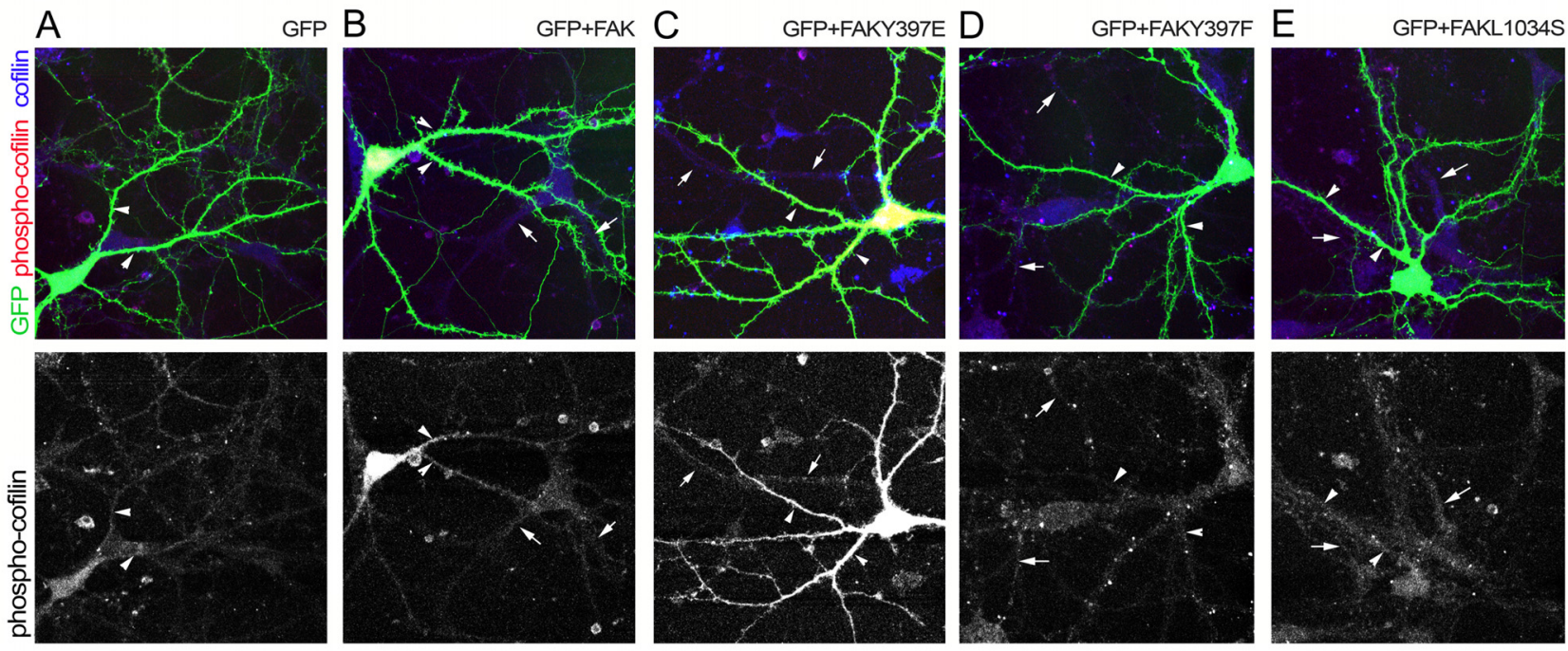

$\mathbf{F}$

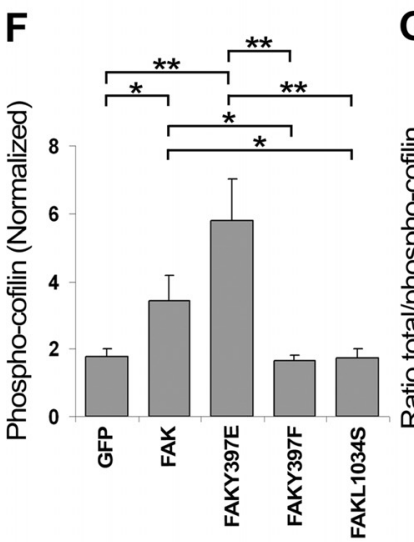

G
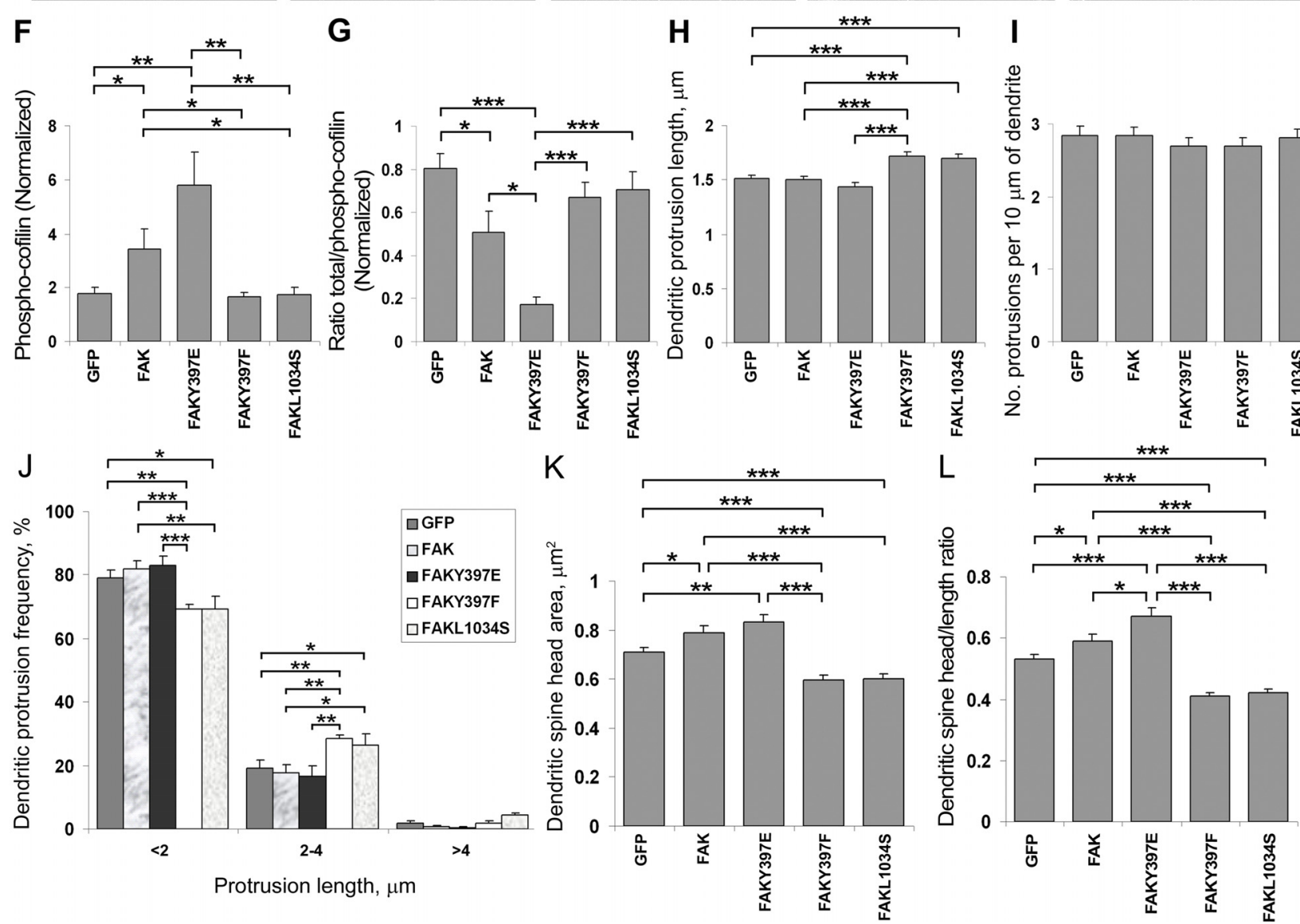

Figure 8. FAK-mediated cofilin phosphorylation depends on FAK activation/phosphorylation and its ability to interact with regulators of Rho family GTPases. $A-E$, Confocal images of 14 DIV hippocampal neurons expressing GFP alone (A), GFP and FAK (GFP + FAK) (B), GFP and FAK ${ }^{\text {Y397E }}$ (GFP + FAKY397E) (C), GFP and FAK ${ }^{\text {Y397F }}$ (GFP + FAKY397F) (D), or GFP and FAK ${ }^{\text {L } 10345}$ (GFP + FAKL1034S) (E). Neurons were obtained from E15 hippocampi of wt mice, transfected at 12 DIV, and processed for indirect immunofluorescence at 14 DIV. Dendritic spine morphology was observed with GFP fluorescence (green), and the distribution of phospho-cofilin (red) and total cofilin (blue) was detected by immunostaining. Scale bar, $10 \mu \mathrm{m} . F$, G, Quantification of phospho-cofilin levels $(\boldsymbol{F})$ and the cofilin/phospho-cofilin ratio (G) in dendrites of transfected (GFP-positive) and control (GFP-negative) neurons. The levels of phospho-cofilin and cofilin were quantified by densitometry. Experimental values represent mean $\pm \operatorname{SEM}\left(n=20\right.$ dendrites from 5 neurons per group; $\left.{ }^{*} p<0.05 ;{ }^{* *} p<0.01 ;{ }^{* * *} p<0.001\right) . \boldsymbol{H}-\boldsymbol{L}$, Quantification of dendritic spine length $(\boldsymbol{H})$; dendritic spine density (I); distribution of dendritic protrusion lengths: $<2 \mu \mathrm{m}, 2-4 \mu \mathrm{m}$, and $>4 \mu \mathrm{m}(\boldsymbol{J})$; dendritic spine head area $(\boldsymbol{K})$; and spine head-area-to-length ratio $(\boldsymbol{L})$. Error bars indicate SEM $(n=$ 500 dendritic protrusions from 5 neurons per group; $\left.{ }^{*} p<0.05 ;{ }^{* *} p<0.01 ;{ }^{* * *} p<0.001\right)$.

1999). LIMK-1 has been shown to be involved in dendritic spine development, as LIMK-1 KO mice fail to form morphologically mature dendritic spines (Meng et al., 2002). Rather, neurons from these knock-outs form thin spines with small heads and postsynaptic densities, similar in morphology to those seen in EphB1/2/3 triple KOs (Henkemeyer et al., 2003). The inhibition of LIMK translation by microRNA-134 also resulted in smaller spine heads (Schratt et al., 2006). LIMK-1 may stabilize the actin 
A
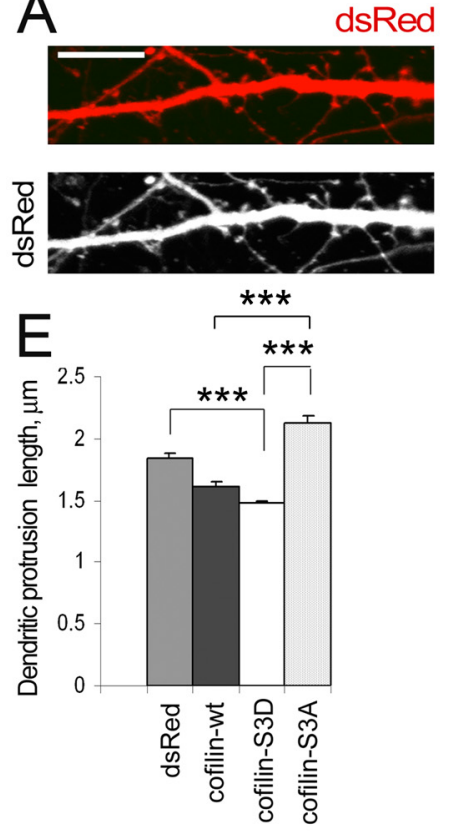
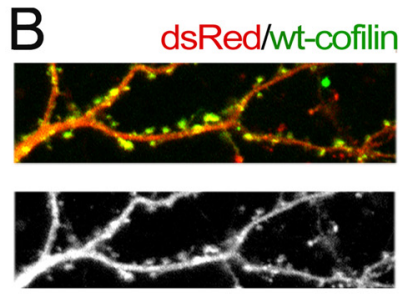

$\mathrm{F}$

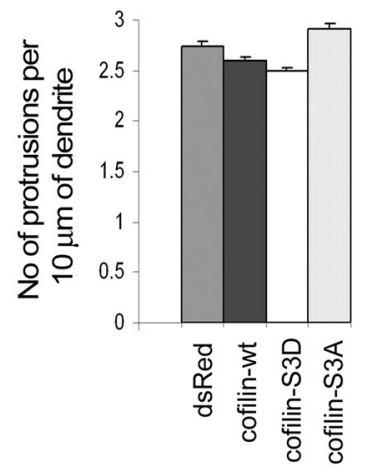

$12+2$ DIV hippocampal neurons
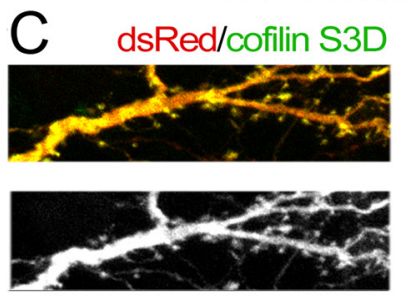

G

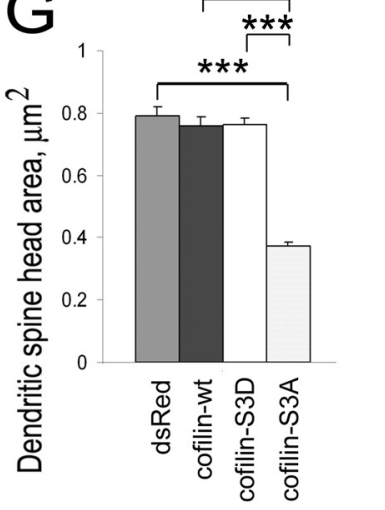

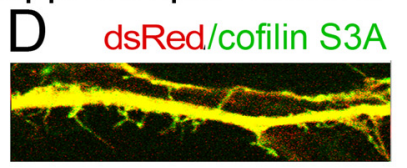

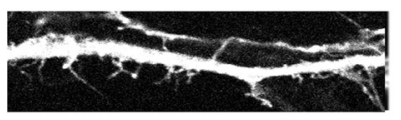

$\mathrm{H}$

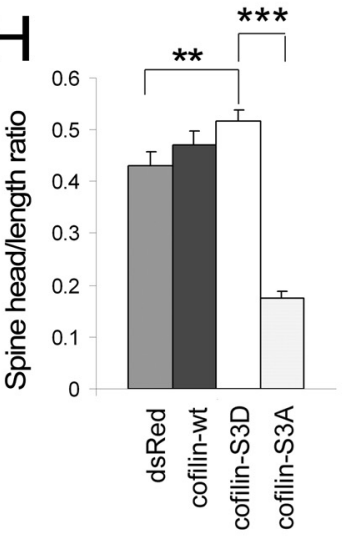

Figure 9. The constitutively active cofilin ${ }^{S 3 A}$ mutant, but not the inactive cofilin ${ }^{53 \mathrm{D}}$ mutant or wt-cofilin, induces immature dendritic spines. $\boldsymbol{A}-\boldsymbol{D}$, Confocal images of 14 DIV hippocampal neurons expressing dsRed alone (A), dsRed with GFP-wt-cofilin (B), dsRed with GFP-cofilin ${ }^{\mathrm{S3D}}(\boldsymbol{C})$, or dsRed with GFP-cofilin ${ }^{\text {S3A }}$ (D). Scale bar, $10 \mu \boldsymbol{\mu m}$. $\boldsymbol{E}$ - $\boldsymbol{H}$, Quantification of dendritic protrusion length $(\boldsymbol{E})$, dendritic protrusion density $(\boldsymbol{F})$, dendritic spine head area $(\boldsymbol{G})$, and spine head-to-length ratio $(\boldsymbol{H})$. Error bars indicate SEM ( $n=300$ dendritic protrusions from $7-10$ neurons per group); ${ }^{* *} p<0.01$; ${ }^{* * *} p<0.001$. The overexpression of the constitutively active nonphosphorylatable cofilin ${ }^{\mathrm{S3A}}$ mutant, but not the dominant-negative phosphomimetic cofilin ${ }^{\mathrm{S3D}}$ mutant or wt-cofilin, prompted the reversion of mushroom-shaped mature spines into thin spines with small heads.

cytoskeleton in mature dendritic spines by inhibiting cofilin activity. Our findings suggest that EphB2-mediated dendritic spine stabilization may rely on the ability of EphB2 receptors to activate the RhoA-ROCK-LIMK-1 pathway that works to suppress cofilin activity and inhibits cofilin-mediated dendritic spine remodeling.

Cofilin is an actin-severing protein that preferentially binds ADP-actin subunits, twisting and breaking preexisting actin filaments. This increases pool of G-actin monomers used by actin polymerizing factors and also creates free barbed ends on preexisting actin filaments, resulting in their elongation (Bamburg, 1999; Condeelis, 2001; Suetsugu et al., 2002; Sarmiere and Bamburg, 2004). Low levels of cofilin activity are detected in resting cells and contribute to F-actin depolymerization at the pointed ends and F-actin polymerization at the barbed ends, resulting in F-actin turnover at slow rate, steady state. On the other hand, enhanced cofilin activity is often detected in ruffling membranes and at the leading edge of migrating cells leading to fast F-actin dynamics. Cofilin activity is regulated by phosphorylation. LIMK-1 suppresses cofilin activity by phosphorylation on serine 3, which inhibits cofilin binding to F-actin. The cofilin-specific phosphatase slingshot dephosphorylates and activates cofilin. Thus, the action of cofilin in cells depends on its phosphorylation state (Andrianantoandro and Pollard, 2006). In synapses, enhanced cofilin activity could induce remodeling of actin-rich stable dendritic spines, their elongation and extension of new filopodia, while low cofilin activity would support F-actin maintenance in mature spines.

We have shown here that a constitutively active nonphosphorylatable cofilin ${ }^{\mathrm{S} 3 \mathrm{~A}}$, but not wt-cofilin, induced remodeling of established mature dendritic spines and extension of new filopodia, suggesting the existence of a signaling mechanism that downregulates cofilin activity in mature spines. Our results demonstrate that EphB2 activation in 14 DIV hippocampal neurons induced cofilin phosphorylation and LIMK-1 activation as demonstrated by increased level of LIMK-1 phosphorylation (Fig. 7). Moreover, ephrin-B2-induced cofilin phosphorylation was inhibited with a specific ROCK inhibitor, Y27632, suggesting that EphB-mediated regulation of cofilin activity at least partially depends on the activation of ROCK and LIMK-1. EphB receptors can also regulate Racl activity in dendritic spines through Rac exchange factors, kalirin-7 and Tiam1 (Penzes et al., 2003; Tolias et al., 2007). Moreover, the Rac-Pak-LIMK pathway was recently suggested to contribute to SynGAP-mediated regulation of steady-state cofilin phosphorylation in dendritic spines (Carlisle et al., 2008). Therefore, it is possible that the Pak-LIMK pathway may also contribute to EphB-mediated regulation of cofilin phosphorylation in dendritic spines. If the regulation of cofilin activity by phosphorylation is the mechanism behind the spinestabilizing effect of the EphB2-FAK-LIMK pathway, then interference at any point in this pathway would lead to lower LIMK activity and/or higher slingshot activity, shifting the phosphocofilin/cofilin equilibrium toward cofilin dephosphorylation, thereby inducing cofilin-mediated dendritic spine remodeling. Then overexpressing the phosphomimetic cofilin ${ }^{\mathrm{S} 3 \mathrm{D}}$ might restore phospho-cofilin/cofilin equilibrium by inhibiting dephosphorylation of endogenous phospho-cofilin, rescuing the mature spine morphology. Indeed, the inhibition of EphB2 activity by overexpressing dnEphB2 or Cre-mediated fak deletion induced dendritic spine remodeling and phosphomimetic cofilin ${ }^{\mathrm{S} 3 \mathrm{D}}$ restored mature dendritic spine phenotype. Our findings suggest that EphB2-FAK pathway promotes dendritic spine stability at least partially through LIMK-mediated cofilin phosphorylation. However, role of cofilin phosphatase SSH in EphB2-mediated 


\section{2 + 2 DIV hippocampal neurons}
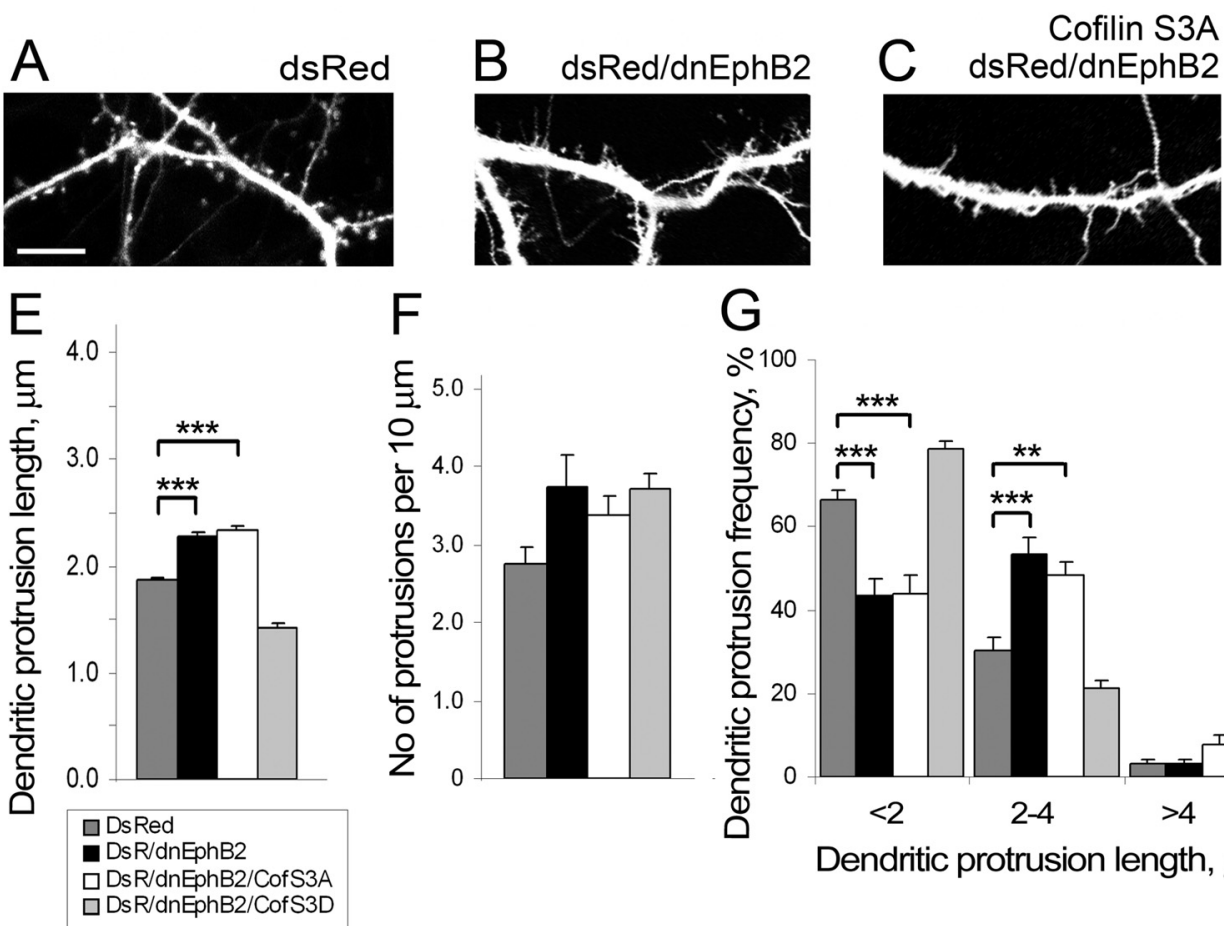

G
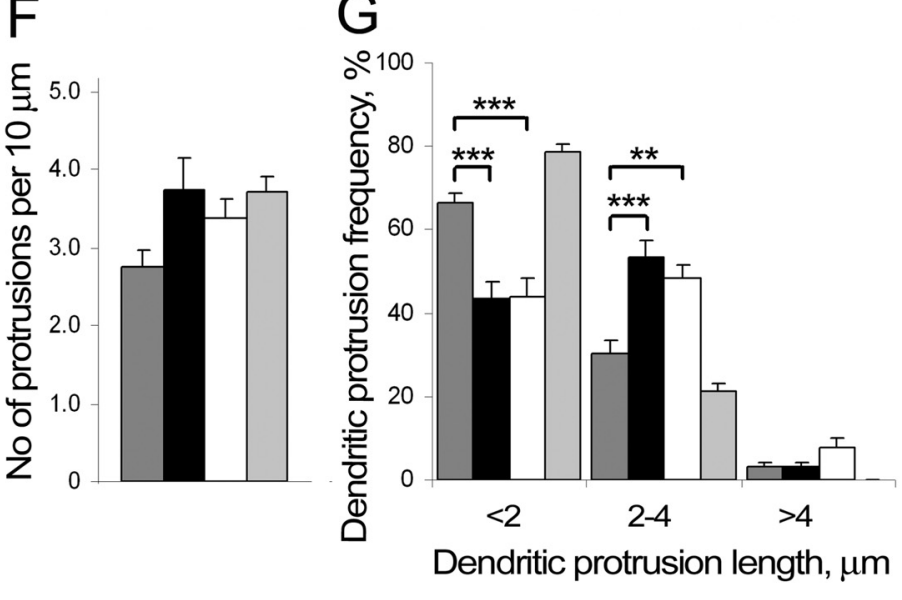

Dendritic protrusion length, $\mu \mathrm{m}$
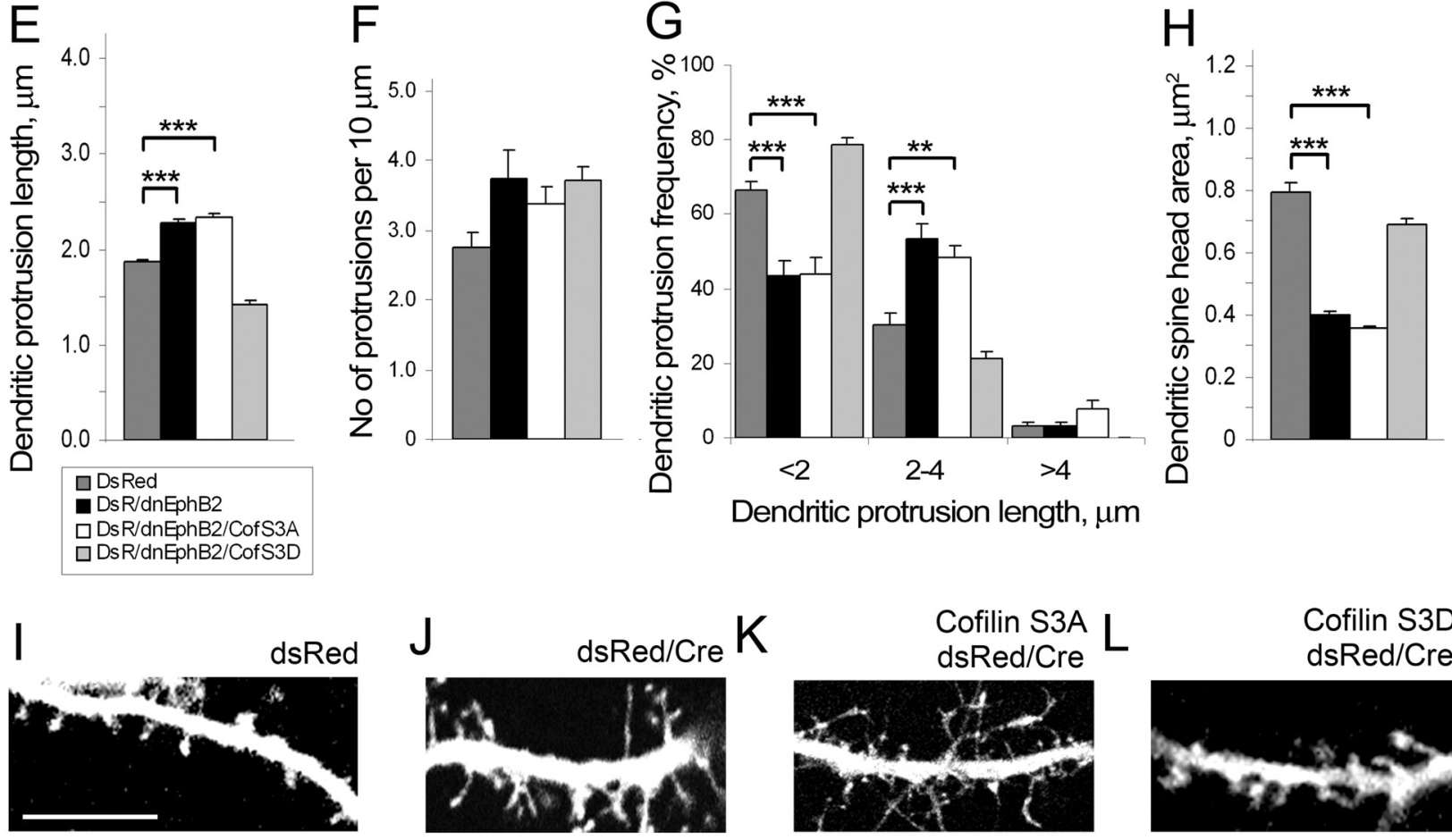

K
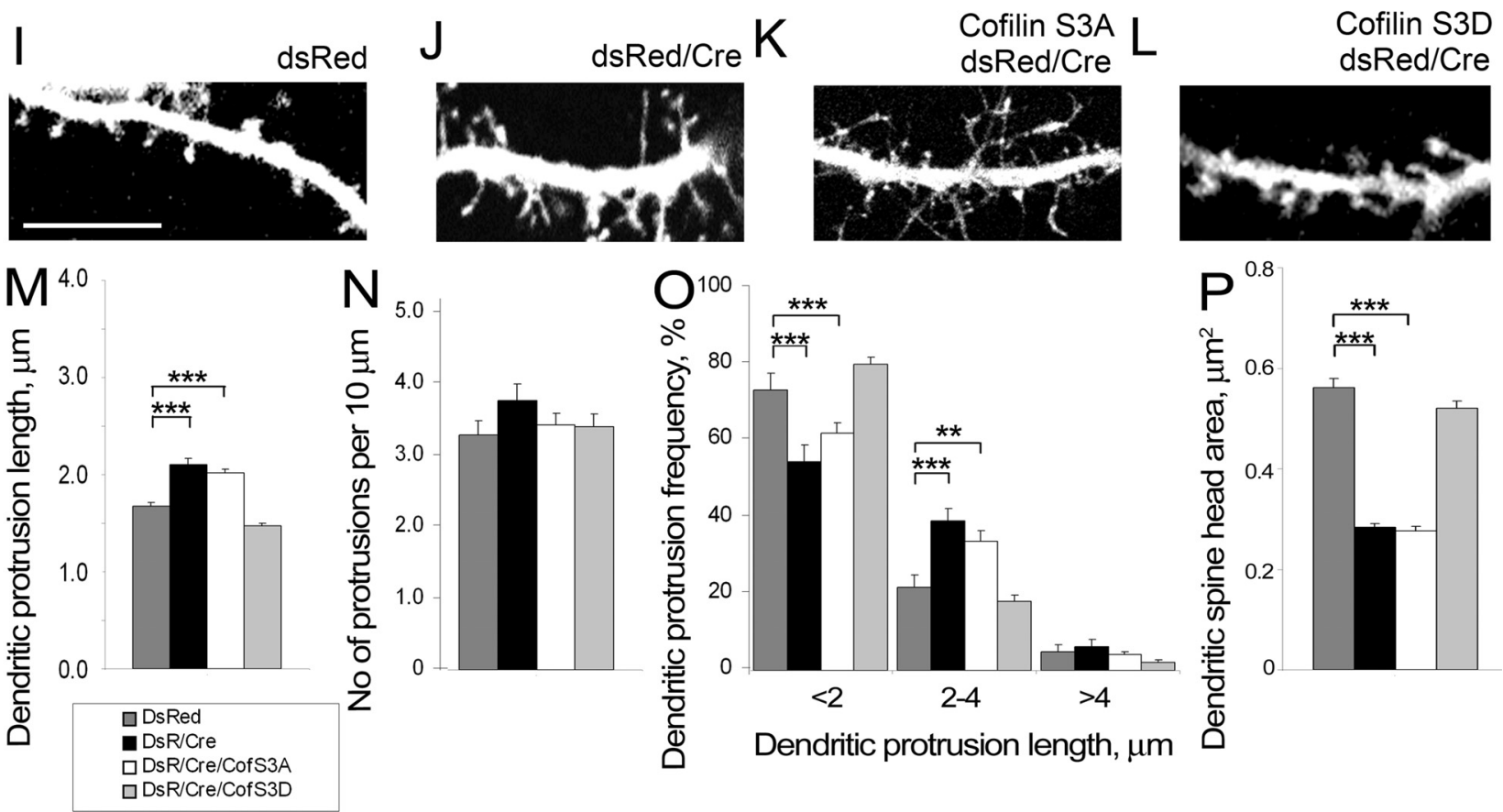

Figure 10. Cofilin inactivation restores mature dendritic spines in hippocampal neurons with inhibited EphB receptor activity or Cre-mediated fak K0. $\boldsymbol{A}-\boldsymbol{D}$, I-L, Confocal images of 14 DIV hippocampal neurons expressing dsRed alone (dsRed) (A); dsRed and dnEphB2 ${ }^{\mathrm{K} 662 \mathrm{R}}$ (dsRed/dnEphB2) (B); dsRed, dnEphB2 ${ }^{\mathrm{K} 662 \mathrm{R}}$, and GFP-cofilin ${ }^{\mathrm{S3A}}$ (dsRed/dnEphB2/cofilinS3A) (C); dsRed, $\mathrm{dnEphB2}^{\mathrm{K} 662 \mathrm{R}}$, and GFP-cofilin ${ }^{\text {S3D }}$ (dsRed/dnEphB2/cofilinS3D) (D); dsRed alone (dsRed) (I);dsRed and Cre (dsRed/Cre) (J); dsRed, Cre, and GFP-cofilin ${ }^{\text {S3A }}$ (dsRed/Cre/CofilinS3A) (K); or dsRed, Cre, and GFP-cofilin ${ }^{\text {S3D }}$ (dsRed/Cre/CofilinS3D) (L). Scale bar, $10 \mu \mathrm{m}$. $\boldsymbol{E}-\boldsymbol{H}, \boldsymbol{M}-\boldsymbol{P}$, Quantification of average dendritic protrusion length $(\boldsymbol{E}, \boldsymbol{M})$; dendritic protrusion density $(\boldsymbol{F}, \boldsymbol{N})$; distribution of dendritic protrusion lengths: $<2 \mu \mathrm{m}, 2-4 \mu \mathrm{m}$, and $>4 \mu \mathrm{m}(\mathbf{G}, \mathbf{0})$; and dendritic spine head area $(\boldsymbol{H}, \boldsymbol{P})$. Error bars indicate SEM $\left(n=500-800\right.$ dendritic protrusions from 7-10 neurons per group); ${ }^{* *} p<$

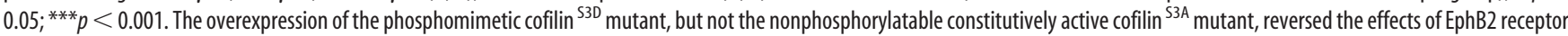
inactivation and Cre-mediated deletion of fak on dendritic spine morphology.

increase in cofilin phosphorylation is still unclear. Moreover, EphA4 receptor has been recently shown to modulate the association of cofilin with the plasma membrane by regulating phospholipase C activity (Zhou et al., 2007). Future studies will deter- mine whether the EphB receptors also regulate the activity of SSH and PLC.

Recent evidence reveals that long-term potentiation (LTP) occurs within individual synapses, and that actin reorganization 
underlies synaptic plasticity (Carlisle and Kennedy, 2005; Lin et al., 2005; Kramár et al., 2006; Chen et al., 2007; Fedulov et al., 2007; Lynch et al., 2007; Rex et al., 2007; Becker et al., 2008). The effects of FAK depletion on actin organization, mature spine morphology, and the regulation of cofilin suggest that FAK signaling and cofilin phosphorylation may contribute to synaptic plasticity. Indeed, FAK was reported to play a role in LTP induction in the dentate gyrus (Yang et al., 2003), and the importance of cofilin phosphorylation in synaptic plasticity during LTP induction, as well as the protective effects of a phosphomimetic cofilin $^{\mathrm{S} 3 \mathrm{D}}$ mutant against $\mathrm{A} \beta$-mediated spine loss, have been recently reported (Chen et al., 2007; Shankar et al., 2007). Moreover, two key upstream regulators of FAK activity in dendritic spines, EphB receptors and integrins, also play important roles in synaptogenesis, synaptic scaling, plasticity, and LTP (Dalva et al., 2000; Chavis and Westbrook, 2001; Chun et al., 2001; Ethell et al., 2001; Grunwald et al., 2001; Henderson et al., 2001; Contractor et al., 2002; Penzes et al., 2003; Gall and Lynch, 2004; Huang et al., 2006; Kramár et al., 2006; Webb et al., 2007; Cingolani et al., 2008).

Our findings conclusively demonstrate that EphB receptors control stability of mature dendritic spines, in part, by suppressing cofilin activity through recruitment/activation of FAK and cofilin phosphorylation. Future studies will determine whether the mechanisms by which this pathway regulates maintenance of mature dendritic spines also orchestrate structural changes in dendritic spines that underlie synaptic plasticity and LTP.

\section{References}

Abbi S, Guan JL (2002) Focal adhesion kinase: protein interactions and cellular functions. Histol Histopathol 17:1163-1171.

Andrianantoandro E, Pollard TD (2006) Mechanism of actin filament turnover by severing and nucleation at different concentrations of ADF/cofilin. Mol Cell 24:13-23.

Arber S, Barbayannis FA, Hanser H, Schneider C, Stanyon CA, Bernard O, Caroni P (1998) Regulation of actin dynamics through phosphorylation of cofilin by LIM-kinase. Nature 393:805-809.

Asrar S, Meng Y, Zhou Z, Todorovski Z, Huang WW, Jia Z (2009) Regulation of hippocampal long-term potentiation by $\mathrm{p} 21$-activated protein kinase 1 (PAK1). Neuropharmacology 56:73-80.

Bamburg JR (1999) Proteins of the ADF/cofilin family: essential regulators of actin dynamics. Annu Rev Cell Dev Biol 15:185-230.

Becker N, Wierenga CJ, Fonseca R, Bonhoeffer T, Nägerl UV (2008) LTD induction causes morphological changes of presynaptic boutons and reduces their contacts with spines. Neuron 60:590-597.

Beggs HE, Schahin-Reed D, Zang K, Goebbels S, Nave KA, Gorski J, Jones KR, Sretavan D, Reichardt LF (2003) FAK deficiency in cells contributing to the basal lamina results in cortical abnormalities resembling congenital muscular dystrophies. Neuron 40:501-514.

Carlisle HJ, Kennedy MB (2005) Spine architecture and synaptic plasticity. Trends Neurosci 28:182-187.

Carlisle HJ, Manzerra P, Marcora E, Kennedy MB (2008) SynGAP regulates steady-state and activity-dependent phosphorylation of cofilin. J Neurosci 28:13673-13683.

Chavis P, Westbrook G (2001) Integrins mediate functional pre- and postsynaptic maturation at a hippocampal synapse. Nature 411:317-321.

Chen LY, Rex CS, Casale MS, Gall CM, Lynch G (2007) Changes in synaptic morphology accompany actin signaling during LTP. J Neurosci 27:5363-5372.

Chun D, Gall CM, Bi X, Lynch G (2001) Evidence that integrins contribute to multiple stages in the consolidation of long term potentiation in rat hippocampus. Neuroscience 105:815-829.

Cingolani LA, Thalhammer A, Yu LM, Catalano M, Ramos T, Colicos MA, Goda Y (2008) Activity-dependent regulation of synaptic AMPA receptor composition and abundance by beta3 integrins. Neuron 58:749-762.

Condeelis J (2001) How is actin polymerization nucleated in vivo? Trends Cell Biol 11:288-293.

Contestabile A, Bonanomi D, Burgaya F, Girault JA, Valtorta F (2003) Lo- calization of focal adhesion kinase isoforms in cells of the central nervous system. Int J Dev Neurosci 21:83-93.

Contractor A, Rogers C, Maron C, Henkemeyer M, Swanson GT, Heinemann SF (2002) Trans-synaptic Eph receptor-ephrin signaling in hippocampal mossy fiber LTP. Science 296:1864-1869.

Cowan CA, Henkemeyer M (2001) The SH2/SH3 adaptor Grb4 transduces B-ephrin reverse signals. Nature 413:174-179.

Dalva MB, Takasu MA, Lin MZ, Shamah SM, Hu L, Gale NW, Greenberg ME (2000) EphB receptors interact with NMDA receptors and regulate excitatory synapse formation. Cell 103:945-956.

Edwards DC, Sanders LC, Bokoch GM, Gill GN (1999) Activation of LIMkinase by Pak1 couples Rac/Cdc42 GTPase signaling to actin cytoskeletal dynamics. Nat Cell Biol 1:253-259.

Ethell IM, Pasquale EB (2005) Molecular mechanisms of dendritic spine development and remodeling. Prog Neurobiol 75:161-205.

Ethell IM, Irie F, Kalo MS, Couchman JR, Pasquale EB, Yamaguchi Y (2001) EphB/syndecan-2 signaling in dendritic spine morphogenesis. Neuron 31:1001-1013.

Fedulov V, Rex CS, Simmons DA, Palmer L, Gall CM, Lynch G (2007) Evidence that long-term potentiation occurs within individual hippocampal synapses during learning. J Neurosci 27:8031-8039.

Fischer M, Kaech S, Knutti D, Matus A (1998) Rapid actin-based plasticity in dendritic spines. Neuron 20:847-854.

Gall CM, Lynch G (2004) Integrins, synaptic plasticity and epileptogenesis. Adv Exp Med Biol 548:12-33.

Govek EE, Newey SE, Akerman CJ, Cross JR, Van der Veken L, Van Aelst L (2004) The X-linked mental retardation protein oligophrenin-1 is required for dendritic spine morphogenesis. Nat Neurosci 7:364-372.

Grunwald IC, Korte M, Wolfer D, Wilkinson GA, Unsicker K, Lipp HP, Bonhoeffer T, Klein R (2001) Kinase-independent requirement of EphB2 receptors in hippocampal synaptic plasticity. Neuron 32:1027-1040.

Harris KM (1999) Structure, development, and plasticity of dendritic spines. Curr Opin Neurobiol 9:343-348.

Henderson JT, Georgiou J, Jia Z, Robertson J, Elowe S, Roder JC, Pawson T (2001) The receptor tyrosine kinase EphB2 regulates NMDA-dependent synaptic function. Neuron 32:1041-1056.

Henkemeyer M, Itkis OS, Ngo M, Hickmott PW, Ethell IM (2003) Multiple EphB receptor tyrosine kinases shape dendritic spines in the hippocampus. J Cell Biol 163:1313-1326.

Hering H, Sheng M (2001) Dendritic spines: structure, dynamics and regulation. Nat Rev Neurosci 2:880-888.

Hildebrand JD, Taylor JM, Parsons JT (1996) An SH3 domain-containing GTPase-activating protein for Rho and Cdc42 associates with focal adhesion kinase. Mol Cell Biol 16:3169-3178.

Huang Z, Shimazu K, Woo NH, Zang K, Müller U, Lu B, Reichardt LF (2006) Distinct roles of the $\beta 1$-class integrins at the developing and the mature hippocampal excitatory synapse. J Neurosci 26:11208-11219.

Irie F, Okuno M, Pasquale EB, Yamaguchi Y (2005) EphrinB-EphB signaling regulates clathrin-mediated endocytosis through tyrosine phosphorylation of synaptojanin 1. Nat Cell Biol 7:501-509.

Iwanicki MP, Vomastek T, Tilghman RW, Martin KH, Banerjee J, Wedegaertner PB, Parsons JT (2008) FAK, PDZ-RhoGEF and ROCKII cooperate to regulate adhesion movement and trailing-edge retraction in fibroblasts. J Cell Sci 121:895-905.

Jiang M, Chen G (2006) High Ca2+-phosphate transfection efficiency in low-density neuronal cultures. Nat Protoc 1:695-700.

Kayser MS, Nolt MJ, Dalva MB (2008) EphB receptors couple dendritic filopodia motility to synapse formation. Neuron 59:56-69.

Kramár EA, Lin B, Rex CS, Gall CM, Lynch G (2006) Integrin-driven actin polymerization consolidates long-term potentiation. Proc Natl Acad Sci U S A 103:5579-5584.

Li W, Lee J, Vikis HG, Lee SH, Liu G, Aurandt J, Shen TL, Fearon ER, Guan JL, Han M, Rao Y, Hong K, Guan KL (2004) Activation of FAK and Src are receptor-proximal events required for netrin signaling. Nat Neurosci 7:1213-1221.

Lin B, Kramár EA, Bi X, Brucher FA, Gall CM, Lynch G (2005) Theta stimulation polymerizes actin in dendritic spines of hippocampus. J Neurosci 25:2062-2069.

Lippman J, Dunaevsky A (2005) Dendritic spine morphogenesis and plasticity. J Neurobiol 64:47-57. 
Luo L (2002) Actin cytoskeleton regulation in neuronal morphogenesis and structural plasticity. Annu Rev Cell Dev Biol 18:601-635.

Lynch G, Rex CS, Gall CM (2007) LTP consolidation: Substrates, explanatory power, and functional significance. Neuropharmacology 52:12-23.

Maekawa M, Ishizaki T, Boku S, Watanabe N, Fujita A, Iwamatsu A, Obinata T, Ohashi K, Mizuno K, Narumiya S (1999) Signaling from Rho to the actin cytoskeleton through protein kinases ROCK and LIM-kinase. Science 285:895-898.

Matus A (2000) Actin-based plasticity in dendritic spines. Science 290:754-758.

Menegon A, Burgaya F, Baudot P, Dunlap DD, Girault JA, Valtorta F (1999) FAK + and PYK2/CAKbeta, two related tyrosine kinases highly expressed in the central nervous system: similarities and differences in the expression pattern. Eur J Neurosci 11:3777-3788.

Meng Y, Zhang Y, Tregoubov V, Janus C, Cruz L, Jackson M, Lu WY, MacDonald JF, Wang JY, Falls DL, Jia Z (2002) Abnormal spine morphology and enhanced LTP in LIMK-1 knockout mice. Neuron 35:121-133.

Miao H, Wei BR, Peehl DM, Li Q, Alexandrou T, Schelling JR, Rhim JS, Sedor JR, Burnett E, Wang B (2001) Activation of EphA receptor tyrosine kinase inhibits the Ras/MAPK pathway. Nat Cell Biol 3:527-530.

Mitra SK, Hanson DA, Schlaepfer DD (2005) Focal adhesion kinase: in command and control of cell motility. Nat Rev Mol Cell Biol 6:56-68.

Moeller ML, Shi Y, Reichardt LF, Ethell IM (2006) EphB receptors regulate dendritic spine morphogenesis through the recruitment/phosphorylation of focal adhesion kinase and RhoA activation. J Biol Chem 281:1587-1598.

Nikolopoulos SN, Giancotti FG (2005) Netrin-integrin signaling in epithelial morphogenesis, axon guidance and vascular patterning. Cell Cycle 4:e131-135.

Parsons JT (2003) Focal adhesion kinase: the first ten years. J Cell Sci 116:1409-1416

Parsons JT, Martin KH, Slack JK, Taylor JM, Weed SA (2000) Focal adhesion kinase: a regulator of focal adhesion dynamics and cell movement. Oncogene 19:5606-5613.

Penzes P, Beeser A, Chernoff J, Schiller MR, Eipper BA, Mains RE, Huganir RL (2003) Rapid induction of dendritic spine morphogenesis by transsynaptic ephrinB-EphB receptor activation of the Rho-GEF kalirin. Neuron 37:263-274.

Ren XR, Ming GL, Xie Y, Hong Y, Sun DM, Zhao ZQ, Feng Z, Wang Q, Shim S, Chen ZF, Song HJ, Mei L, Xiong WC (2004) Focal adhesion kinase in netrin-1 signaling. Nat Neurosci 7:1204-1212.

Rex CS, Lin CY, Kramár EA, Chen LY, Gall CM, Lynch G (2007) Brainderived neurotrophic factor promotes long-term potentiation-related cytoskeletal changes in adult hippocampus. J Neurosci 27:3017-3029.

Rico B, Beggs HE, Schahin-Reed D, Kimes N, Schmidt A, Reichardt LF (2004) Control of axonal branching and synapse formation by focal adhesion kinase. Nat Neurosci 7:1059-1069.

Saneyoshi T, Wayman G, Fortin D, Davare M, Hoshi N, Nozaki N, Natsume T, Soderling TR (2008) Activity-dependent synaptogenesis: regulation by a CaM-kinase kinase/CaM-kinase I/ $\beta$ PIX signaling complex. Neuron 57:94-107.

Sarmiere PD, Bamburg JR (2004) Regulation of the neuronal actin cytoskeleton by ADF/cofilin. J Neurobiol 58:103-117.

Schaller MD, Hildebrand JD, Shannon JD, Fox JW, Vines RR, Parsons JT (1994) Autophosphorylation of the focal adhesion kinase, pp125FAK, directs SH2-dependent binding of pp60src. Mol Cell Biol 14:1680-1688.

Schratt GM, Tuebing F, Nigh EA, Kane CG, Sabatini ME, Kiebler M, Greenberg ME (2006) A brain-specific microRNA regulates dendritic spine development. Nature 439:283-289.

Shankar GM, Bloodgood BL, Townsend M, Walsh DM, Selkoe DJ, Sabatini
BL (2007) Natural oligomers of the Alzheimer amyloid- $\beta$ protein induce reversible synapse loss by modulating an NMDA-type glutamate receptor-dependent signaling pathway. J Neurosci 27:2866-2875.

Sheng M, Hoogenraad CC (2007) The postsynaptic architecture of excitatory synapses: a more quantitative view. Annu Rev Biochem 76:823-847.

Shi Y, Ethell IM (2006) Integrins control dendritic spine plasticity in hippocampal neurons through NMDA receptor and $\mathrm{Ca}^{2+} /$ calmodulindependent protein kinase II-mediated actin reorganization. J Neurosci 26:1813-1822.

Suetsugu S, Miki H, Takenawa T (2002) Spatial and temporal regulation of actin polymerization for cytoskeleton formation through Arp $2 / 3 \mathrm{com}$ plex and WASP/WAVE proteins. Cell Motil Cytoskeleton 51:113-122.

Sumi T, Matsumoto K, Takai Y, Nakamura T (1999) Cofilin phosphorylation and actin cytoskeletal dynamics regulated by Rho- and Cdc42activated LIM-kinase 2. J Cell Biol 147:1519-1532.

Tolias KF, Bikoff JB, Kane CG, Tolias CS, Hu L, Greenberg ME (2007) The Rac1 guanine nucleotide exchange factor Tiam 1 mediates EphB receptordependent dendritic spine development. Proc Natl Acad Sci U S A 104:7265-7270

Torsoni AS, Marin TM, Velloso LA, Franchini KG (2005) RhoA/ROCK signaling is critical to FAK activation by cyclic stretch in cardiac myocytes. Am J Physiol Heart Circ Physiol 289:H1488-H1496.

van Galen EJ, Ramakers GJ (2005) Rho proteins, mental retardation and the neurobiological basis of intelligence. Prog Brain Res 147:295-317.

Webb DJ, Donais K, Whitmore LA, Thomas SM, Turner CE, Parsons JT, Horwitz AF (2004) FAK-Src signalling through paxillin, ERK and MLCK regulate adhesion disassembly. Nat Cell Biol 6:154-161.

Webb DJ, Zhang H, Majumdar D, Horwitz AF (2007) Alpha5 integrin signaling regulates the formation of spines and synapses in hippocampal neurons. J Biol Chem 282:6929-6935.

Wegner AM, Nebhan CA, Hu L, Majumdar D, Meier KM, Weaver AM, Webb DJ (2008) N-wasp and the arp2/3 complex are critical regulators of actin in the development of dendritic spines and synapses. J Biol Chem 283:15912-15920.

Xie Z, Srivastava DP, Photowala H, Kai L, Cahill ME, Woolfrey KM, Shum CY, Surmeier DJ, Penzes P (2007) Kalirin-7 controls activity-dependent structural and functional plasticity of dendritic spines. Neuron 56:640-656.

Yang N, Higuchi O, Ohashi K, Nagata K, Wada A, Kangawa K, Nishida E, Mizuno K (1998) Cofilin phosphorylation by LIM-kinase 1 and its role in Rac-mediated actin reorganization. Nature 393:809-812.

Yang YC, Ma YL, Chen SK, Wang CW, Lee EH (2003) Focal adhesion kinase is required, but not sufficient, for the induction of long-term potentiation in dentate gyrus neurons in vivo. J Neurosci 23:4072-4080.

Yuste R, Bonhoeffer T (2001) Morphological changes in dendritic spines associated with long-term synaptic plasticity. Annu Rev Neurosci 24:1071-1089.

Zhai J, Lin H, Nie Z, Wu J, Cañete-Soler R, Schlaepfer WW, Schlaepfer DD (2003) Direct interaction of focal adhesion kinase with p190RhoGEF. J Biol Chem 278:24865-24873.

Zhang H, Webb DJ, Asmussen H, Niu S, Horwitz AF (2005) A GIT1/PIX/ $\mathrm{Rac} / \mathrm{PAK}$ signaling module regulates spine morphogenesis and synapse formation through MLC. J Neurosci 25:3379-3388.

Zhou L, Martinez SJ, Haber M, Jones EV, Bouvier D, Doucet G, Corera AT, Fon EA, Zisch AH, Murai KK (2007) EphA4 signaling regulates phospholipase $\mathrm{C} \gamma 1$ activation, cofilin membrane association, and dendritic spine morphology. J Neurosci 27:5127-5138.

Zhou Z, Meng Y, Asrar S, Todorovski Z, Jia Z (2009) A critical role of Rhokinase ROCK2 in the regulation of spine and synaptic function. Neuropharmacology 56:81-89. 